\title{
WHO'S LAUGHING NOW? \\ SURVIVORS OF SEXUAL VIOLENCE JOKE ABOUT RAPE
}

\author{
by \\ Anna Lise Frey \\ Bachelor of Arts, Concordia University, Montréal, Québec, 2014 \\ A thesis \\ presented to Ryerson University and York University \\ in partial fulfillment of the \\ requirements for the degree of \\ Master of Arts \\ in the Program of \\ Communication and Culture
}

Toronto, Ontario, Canada, 2017

(C) Anna Lise Frey 2017 


\section{AUTHOR'S DECLARATION FOR ELECTRONIC SUBMISSION OF A THESIS}

I hereby declare that I am the sole author of this thesis. This is a true copy of the thesis, including any required final revisions, as accepted by my examiners.

I authorize Ryerson University to lend this thesis to other institutions or individuals for the purpose of scholarly research

I further authorize Ryerson University to reproduce this thesis by photocopying or by other means, in total or in part, at the request of other institutions or individuals for the purpose of scholarly research.

I understand that my thesis may be made electronically available to the public. 
ABSTRACT

Who’s Laughing Now? Survivors of Sexual Violence Joke About Rape

\author{
Anna Lise Frey \\ Master of Arts, Communication and Culture \\ Ryerson University and York University, 2017
}

Survivors of sexual violence in Canada face a culture that is largely hostile to their voices and experiences. Despite this, some survivors turn to the public sphere to work through their trauma. This thesis presents interview data from seven survivors who have performed stand-up comedy about their own experiences with sexual violence. It weaves together critical and clinical trauma theories, feminist work on sexual violence, and communications theories about humour and joking to offer new insights into how cultural responses to sexual trauma can work to challenge dominant attitudes about rape. This thesis ultimately argues that the cognitive, linguistic, and affective strategies that joking encourages can guide survivors towards reconceptualising the traumatic events they've experienced and facilitate the integration of those traumas into their lives. By focusing on a novel aspect of survivors' affective expressions - their fun - this analysis works to make better sense of peoples' complex responses to trauma. 


\section{ACKNOWLEDGEMENTS}

I am grateful, above all, to each of the seven participants who entrusted me with their experiences, opinions, and feelings. The time I spent learning from them was inspiring and fortifying - I am endlessly impressed with the work they do and have tried my best to do it justice in these pages.

I am profoundly appreciative to my supervisor, May Friedman, whose faith in my work was bolstering at every turn. Her guidance was always offered with the rare and invaluable combination of empathy and critical insight; I am fortunate to have had her on my side. My readers offered essential feedback during the draft and defence stages of this thesis. I am exceedingly grateful to Art Blake, whose counsel to "stay human" during grad school echoed often through my mind, and to Eva Karpinski, who pointed me towards new methodological and theoretical areas that solidified the foundations of my thesis. Her contributions during my defence were acute and enthusiastic and I am indebted to her engagement with my work. My defence chair, Jennifer Poole, felt somehow immediately familiar - I am thankful for her kindness during a very intense morning.

From Concordia University I am grateful to the good humour and patient encouragements of Ian Reilly, in whose undergraduate seminar my idea for this thesis first uncurled, and to Viviane Namaste, who demonstrated how fun serious scholarship could be.

Members of my cohort, Gabrielle Willms, Emma Sharpe, Leslie Schumacher, and Vanessa Ciccone, took breaks from their own vibrant research for essential picnicking, wineand-cheesing, and one offbeat trip to Oxford.

My success at maintaining a social life outside of the grad school bubble was due only to the good graces of my core four/personal cheer squad, Avery Bellisario, Sangeetha Thillainathan, 
and Jessica Camps-Cooke; my colleague and ally Dahlia Belinsky; and my soul sister Katie LaGrave; who each, along with my aunt Brenda Frey, provided instrumental feedback on my application materials two years ago and have been on call ever since.

I am grateful to my entire family for their endless love, support, and commitment to fun. In particular I would like to thank my Poppa, whose keen interest in his grandchildren's educations kept us all afloat in one way or another over the years, and my Nana, a spirited role model in her own right, for keeping his legacy and love alive. I also thank my mother, Sandra Petersen-Frey, who has been my most committed and generous reader; and my dad, Eric Frey, who gave me his sparkling sense of humour to share - the big doing is done! And, finally, I offer thanks to my spouse, Max Morin, who was perpetually available for proofreading and calls of "what's another word for..." across our workspace; his unrelenting confidence in and affection for me have made life eminently more meaningful. 


\section{DEDICATION}

For all survivors 


\section{TABLE OF CONTENTS}

Abstract $\quad$ iii

Acknowledgments $\quad$ iv

Dedication vi vi vin

INTRODUCTION

$\begin{array}{ll}\text { CHAPTER 1: Literature review } & 6\end{array}$

Perspectives on culture $\quad 6$

Humour 7

Feminist interest in humour and laughter 9

Gender 10

Trauma defined 11

Trauma symptoms

Integrating trauma 13

CHAPTER 2: Methodology 14

Overview 14

Recruitment 14

$\begin{array}{lr}\text { Confidentiality } & 15\end{array}$

Interviewing 16

$\begin{array}{ll}\text { Feminist methods } & 18\end{array}$

CHAPTER 3: Culture and comedy $\quad 22$

Discourses of rape culture $\quad 22$

Material domination of rape culture $\quad 25$

Counter-discourses $\quad 30$

Perspectives on representing trauma

Expanding the emotional archive $\quad 36$

Mechanism of resisting interpellation 38

CHAPTER 4: Experience of the performer $\quad \mathbf{4 0}$

Working through trauma in language $\quad 40$

Benefits of comedic principles

Witnessed repetition of a stand-up set $\quad 48$

Infelicitous $\quad 55$

CHAPTER 5: Survivors in the mainstream $\quad \mathbf{5 8}$

Absence of social scripts for responding to violence

Humour as educational tool $\quad 59$

Reconfiguring social norms $\quad 62$

Impressing a preferred framing $\quad 66$

$\begin{array}{ll}\text { Potential cultural risks } & 72\end{array}$

CHAPTER 6: Between us $\quad \mathbf{7 4}$

Humour and the formation of social groups $\quad 74$

Value of survivors connecting with other survivors 76

$\begin{array}{ll}\text { CONCLUSIONS } & \mathbf{8 7}\end{array}$

$\begin{array}{ll}\text { WORKS CITED } & 90\end{array}$ 


\section{INTRODUCTION}

The incidence of sexual violence in our contemporary Canadian communities is unceasing. Street harassment, rape, childhood sexual abuse, threats of assault, stalking, domestic violence, and other forms of sexual aggression plague the lives of people across the country (Perrault; McDonald et al.). Survivors of these acts of violence are frequently dismissed outright by police officers, lawyers and judges, journalists, academics, family members, and friends (McDonald et al.; Doolittle; Femifesto; Herman 64). Rarely is sexual trauma taken up in legal, scholarly, or cultural discourses with compassion and respect for those who live with it. I have engineered this work as a survivor-led and -centred project to combat the dearth of interdisciplinary trauma-informed academic writing on sexual violence and experiences of survival.

The past year has been a parade of people asking, "What's your research about?" I offered different answers depending on context, timing, and audience. It's about feminist humour. It's about trauma and laughter. It's about rape jokes. Here, in the work itself, something closer to honesty: this research was meant to satisfy my curiosity about what it means to laugh at and about violence inflicted on my own body.

The central question of this project is: how does a pro-survivor genre of joking about sexual violence function as an act of resistance within a culture that condones rape? Furthermore, how are comics who are survivors of sexual violence themselves troubling misogynist, victimblaming rape humour by producing their own emancipatory comedic content? My research and theoretical framework are necessarily interdisciplinary. I take up resistance both in a discursive sense, where speech can work to subvert and oppose dominant power dynamics, as well as in a material sense, where survivors' living bodies signify a refusal to acquiesce to the dominant order that seeks to silence, sequester, and ridicule us. 
As a whole this text indicates the diversity of survivors' lives; rather than the narrow mainstream depictions of survivors of sexual violence, depictions in which we are dead, or pathologically unsmiling, or consumed by our trauma symptoms to the point of madness or hysteria, this work points to a slice of survivors' lives that has been hitherto ignored - our fun. Frequently surprising, sometimes unflattering, and often desperately defiant, survivors' comedy pulls very few of its punches and leans far out past the boundaries of rape culture's comfort zone. The jokes referenced here might be funny on the page, but I recommend viewing the YouTube clips of Heather Jordan Ross and Nelson Mayers's performances before beginning a serious read-through to get a real feel for the material (Jordan Ross; Mayer). These performances provide a generous introduction to the type of comedy referenced throughout - Jordan Ross and Mayer each sift through the personal and cultural implications of sexual violence to craft jokes that are at once provoking and intimately familiar to other survivors. The clips were recorded during the Rape is Real and Everywhere stand-up comedy tour, a show that Jordan Ross coproduced with her colleague Emma Cooper, which travelled across Canada during the spring of 2016.

Chapter 1, the literature review, provides a brief introduction to rape culture. I will point out the intricacies of its workings and hold them to light later, in the main body of the analysis. I've written my review of humour studies in a similar vein; while significantly less politically and emotionally fraught, it seems more effective to avoid front-loading theory at the expense of engaging with it meaningfully in the analysis. I detail my approach to cultural studies and work with theories of language, power, and resistance to define how I approach the possibility of social change. Finally, I sketch out an approach to critical trauma studies that is at once mindful about how trauma lives in the body and attentive to how it informs our social and cultural worlds. 
I concern myself in Chapter 2 with the methodological grounding of my research. In the interest of encouraging further work on these topics, I've written here as transparently as I was able; I detail my recruitment and interview processes here, and outline the supporting theoretical and methodological texts I consulted as I planned my research stage. To draft a survivor-centric project I relied heavily on research generated directly from consultations with other survivors of sexual violence. I take the position that all research is culturally and politically bound and use the feminist emphases on emancipatory research practices and self-reflexivity to guide me towards compassionate and liberatory ends.

The analysis begins in earnest in Chapter 3. Here is a more thorough fleshing-out of rape culture as it currently moves through our social and mediated world. I argue that the ideological domination enjoyed by rape culture is integral to its continued material authority. As such, discourse is a key site in the struggle to subvert and dismantle that authority. Tension emerges during attempts to discursively represent trauma: cultural, trauma, and performance theorists agree that trauma and pain are slippery artefacts that resist representation. Language and performance bump against boundaries of what is intelligible, satisfactory, and accurate for survivors of sexual trauma to communicate. I draw on both verbal and visual representations of sexual violence to structure my arguments, though my later analysis rests primarily on verbal discourses within and about stand-up comedy. Cultural and performance theorists concerned with visual representations of trauma and the body will find a rich archive within the comedy club, but these considerations lay outside the scope of my project. This chapter looks at the trouble with trauma and offers comedy as a resource to fill some of the gaps other modes of performance have struggled to satisfy. 
The following three chapters examine comedy about rape culture performed by survivors of sexual violence from three different perspectives. Chapter 4 investigates the experience of the performers themselves. These pages dig into trauma theory from philosophical, psychotherapeutic, and experiential perspectives. Clinical practitioners, scholars, and survivors agree that working through trauma in language can be a transformative project. Genres with flexible expectations of truth-telling can be particularly useful here since traumatic memory itself often refuses linearity (Gilmore 24; Jensen 435). This chapter suggests that the comedic principles of incongruity and surprise can be beneficial to survivors during this narrativizing process. What is critical for survivors is not only creating a coherent narrative of their trauma, but also sharing that narrative with listeners who are able to receive it with compassion and support. Stand-up comedy facilitates the repetition of that narrative before audiences who can rely on the conventions of a comedy club to offer adequate support in the form of laughter and applause. The impact of the audience can be significant: while an audience that responds positively can be helpful for the comic's therapeutic process, a disparaging or indifferent audience can induce feelings of shame, embarrassment, or regret. Individual comics and show producers must be conscientious of these risks.

Chapter 5 focuses on this humour performed in mainstream clubs where audiences are drawn from the general population and are not anticipating or attending in support of performances about sexual trauma. This chapter concentrates on humour as a tool of education for reconfiguring social norms about sexual violence and for impressing anti-rape ideologies on individuals and groups.

The final chapter of the analysis attends to the dynamics at work when survivors perform their comedy for crowds of other people who live with sexual trauma. One significant impact of 
sexual violence is the fragmentation of a survivor's social world. Opportunities to meet and enjoy the company of other survivors outside of clinical or strictly therapeutic contexts are rare. Humour is an effective tool for forming social bonds; used in this way comedy can create a temporary social pocket where survivors' lives and experiences are explicitly centred and cared for.

This work, like so much feminist work, is both personal and political. Its roots live in my craving for a different way of feeling about trauma, in my insistence that, despite trauma's insidious isolation, I must not be alone in that desire. My language throughout is structured from my constant craving for recognition and community. I extend the first-person and possessive pronouns I use throughout this text as open arms to other survivors reading: these are our struggles; this is $m y$ experience too. The work you will read here has been shaped by the generous staking and guidance of the interview participants who offered me insight into their own personal relationships with trauma, laughter, and culture. This research would not exist without them. By betraying the suffocating cultural codes that both mandate the silencing of all survivors and set us up as open targets for violent rape jokes, these interview participants and stand-up comics validate new modes and methods of moving forward with trauma, ones that mobilize survivors' authority and expertise as we undertake the twin projects of dismantling rape culture while learning to live with our own histories of violence. 
CHAPTER 1: Literature review

Perspectives on culture

In order to maintain its continued material domination any oppressive system must also secure cultural domination over the targeted population. Culture, broadly defined, is the systems of shared meanings, values, traditions, and beliefs that bond groups of people together (Williams, "Culture"). The central project for cultural theorists is to denaturalize culture from human life (Wynter 242). These scholars investigate how cultures are constructed so that they can understand and be critical of how power flows within. Language is a key site in the construction of culture. French philosopher Michel Foucault wrote extensively on language and power, and his use of the term discourse is one I take up here as well. For Foucault, a discourse is a linguistic or semiotic system with a specialized vocabulary and internal logic that shapes the way we think by setting up parameters about what we can and cannot know (Cavanagh). Culture is, in part, a cluster of discourses. People with substantial wealth and social capital are able to circulate their preferred discourses more broadly than those without similar advantages. The dominant class's goal in cultural production is to secure the social cohesion of a population by producing a unitary system of meanings by which the vast majority of people abide (Wynter 244). The translation from discourse to social behaviour is not automatic by any means: people are not simply void receptacles waiting to be indiscriminately filled with information and opinions (Hall 167). Each of us evaluates and integrates or discards new data in line with our previously held values, knowledge, and assumptions. Because we are no "cultural dopes," as Stuart Hall writes, reproduction of the dominant order is most efficient when discursive processes remain unconscious: the naturalization of the current order only benefits those who are already in power (Hall, "Notes" 447). 
Interventions made by cultural theorists and social activists help to interrupt this selfreproducing mechanism. The feminist movement has put names to some of the ways male dominance is asserted: patriarchy refers to the systemic privileging of men's lives and experiences over those of others, and rape culture describes a social environment in which sexual violence is expected and condoned. These are examples of the specialized vocabulary of the feminist counter-discourse. Foucault understands power not as something someone can have, but rather as a dynamic negotiated between players in any given situation (Cavanagh). With regards to counter-discourses and revolution, Foucault writes, "Where there is power, there is resistance, and yet, or rather consequently, this resistance is never in a position of exteriority in relation to power" (History 95). This emphasis on fluidity reflects the shifting nature of culture itself. Williams argues that the basic error of much cultural theory is "the reduction of the social to fixed forms" (Marxism 129). He proposes to supplant the notion of "ideology," which, to him, connotes this fixedness, with the term "structure of feeling." This describes a fundamentally social experience "concerned with meanings and values as they are actively lived and felt" that accounts for the nuances inherent in perpetually developing structures (Williams, Marxism 132). What this flexibility indicates is a relentless possibility for social change. Language, Hall writes, "is both the site and the stake of class struggle" (Hall, "Notes" 453). The work that follows has grown from these perspectives, both in the sophisticated ways that each interview participant articulated their role in the struggle against domination, and in the supporting analysis I have contributed.

Humour

Since language is an integral component to how structures of feeling emerge and develop into dominant cultural systems, it is crucial that scholars attend to it critically in each of its forms. 
Verbal humour, sometimes dismissed as a frivolous mode of communication, deserves to be taken seriously indeed: it can play strategic roles in politics, education, activism, communitybuilding, and conflict resolution (Meyer; Mayo; Rich; Cox; Parvulescu).

Humour's unique rhetorical qualities can provoke listeners into new ways of thinking. Speakers intending to bridge gaps within a divided audience may do so with humour's capacity to delicately clarify the perceived sources of difference and establish common ground while maintaining an air of goodwill and approachability. Cris Mayo refers to this capacity as the ability to make "a meta-level commentary on the fact of different audiences," which is a stepping-stone towards rectifying those initial differences (510). John C. Meyer's analysis of humour as used as a persuasive tool in political communications fleshes out the different relationships a speaker may have with factions of their audience and the different functions humour may play therein. He distinguishes groups based on their levels of familiarity and agreement with a speaker's message and suggests four possible outcomes: audiences with high levels of familiarity and sympathy to a speaker's message will experience identification with the speaker; audiences with slightly lower levels of each may receive clarification of the issues through the use of humour; audiences with some disagreement or unfamiliarity with the speaker's message may experience enforcement of the speaker's desired outcome; and audiences strongly opposed to the speaker's message, "even with great familiarity of the issue," may experience differentiation, or feelings of further exclusion from the speaker and those who agree with them, after the use of humour (Meyer 318). The humour use must be carefully constructed in order to achieve the potential positive (cohesive) outcomes associated with the first three configurations listed and to avoid any needless or unintentional further alienation from or between listeners. Both Walter Benjamin and Foucault celebrate laughter's role in illuminating 
new avenues of thinking: Benjamin claims, "There is no better starting point for thought than laughter," and Foucault credited the initial spark for his book The Order of Things to "the laughter that shattered, as I read the passage [in Borges], all the familiar landmarks of my thought" (Benjamin; Foucault, The Order). Although laughter can often take us by surprise, a listener must first be willing and receptive to the use of humour in order for it to be successful (Meyer 316). Humour will not be effective, or even appropriate, in every situation or for every audience, but skilled communicators will be able to negotiate those boundaries themselves to draw listeners together and step towards a newly common goal.

Feminist interest in humour and laughter

Feminist activists have long recognized and taken up laughter as political action and mechanism of self-care. Rosi Braidotti writes of the "subversive force of Dionysian laughter" and invites modern feminists to partake more liberally in these joyful disruptions (Parvulescu 19). Feminists have recognized laughter's range of applications, from the merrymaking Braidotti desires, to how Annie Leclerc invests laughter with the power of a weapon to pierce and deflate men's values, to Hélène Cixous's claim in her "Laugh of the Medusa" that women's laughter is erotic and generative (Parvulescu 112; Cixous). Despite this work, accusations of humourlessness have been levied at feminists for years. Of course, it is worth remembering who spouted these accusations and which kinds of humour they were defending. Proponents of misogynist, victim-blaming rape jokes have been quick to lambast feminists for our complaints about that content, but then issue threats to silence us once we start telling jokes about our own rapists (Cox). The message is clear: feminists and feminism are to be the butt and nothing but. This insistence on silencing our laughter belies how menacing it can be. Defiant humour and laughter are dangers to the dominant order because they can "affect the stability of meaning and 
the structure of political power" with their disruptive potential (Mayo 513). Attributions of humourlessness come from within feminism as well as from without - we are still posing the question to each other whether it is possible (beneficial?) to have "a feminism that is joyous, relentless, outrageous, libidinally charged" (Ronell, “Interview” 127). I align myself, and have attempted to align this work, as much as possible, with the delightful, disorderly irony Sara Ahmed has embraced by labelling herself a Feminist Killjoy - simultaneously performing an ingroup wink, a smirk, a steady gaze held until the other backs down.

Gender

Patriarchy and rape culture function along gendered lines: they work to preserve hegemonic male masculinity's position of dominance over other modes of gender identity or expression. Women, including trans women, and non-binary people, are most often subjected to sexual violence within this systemic arrangement, but men who deviate from prescribed norms of masculinity - gay or bisexual men, trans men, disabled men - often become targets of violence themselves. I pick up the topic of masculinity and men's experiences of surviving sexual violence again in Chapter 4. Dominant Canadian culture relies on and reaffirms the binary system of gender, meaning that infants are assigned their gender at birth depending on the appearance of their genitals. Boys and girls are raised with different values, educated to conform to different roles, and are subjected to different mechanisms of power. Thanks to the tireless work of trans and queer activists and scholars, the firmness of this binary system is waning, but, like most social change, that shift is happening slowly. This research project is grounded in a theoretical understanding of gender as performative and culturally constructed (Butler, "Critically" 21). Having said that, none of the comics included here identified themselves to me as transgender, non-binary, or otherwise gender diverse, so the bulk of the analysis concentrates 
on cisgender dynamics as they operate according to the dominant binary system. I acknowledge that trans and non-binary people, particularly transwomen, are disproportionately subjected to sexual violence and that this analysis may not adequately hold their experiences. I hope the foundations provided by this project will be of use to future trans and gender diverse scholars interested in exploring their own emancipatory uses of humour.

Trauma defined

Trauma, like humour, is an interdisciplinary field of scholarship. Psychologists, psychiatrists, psychotherapists, and other front-line practitioners work directly with clients who experience trauma in order to understand and alleviate their symptoms (Van der Kolk, Herman); theatre scholars grapple with how to represent trauma in live performance (Duggan); finally, critical cultural theorists are turning towards conceptualizing trauma as "a product of history and politics, subject to reinterpretation, contestation, and intervention" (Wertheimer and Casper 3). Questions about what events constitute trauma and in which bodies trauma is recognized as such have been brought to the forefront. Sexual violence can be understood as a traumatic event as it has the potential to disrupt beliefs in personal safety and bodily autonomy. People who have survived war, epidemic, or natural disasters may experience trauma as a group phenomenon, where the time- and/or space-bound nature of the traumatizing events have led to concentrated impacts on people. Some instantiations of sexual violence have similar implications: we can think of rape used as a tool of war, or of the vicious targeting of Indigenous women and girls for sexual and physical violence in Canada as producing defined groups of survivors. Although these mass offences play a crucial part in informing our global and national understandings of gender and power, they are often considered as distinct from the ongoing everyday sexual violence perpetrated against people worldwide. This splitting contributes to the popular conception that 
sexual violence is largely a personal and private crime between individuals and not, as feminist thinkers and activists continue to assert, a systemic and political phenomenon deserving comparable resources and attention.

Trauma symptoms

The individualizing of sexual violence has implications on how survivors experience symptoms of trauma. In addition to embodied responses to trauma such as depression, anxiety, insomnia, intrusive thoughts or memories including nightmares, emotional numbness, and dissociation, all of which people experience to varying degrees and with varying consistency, survivors of sexual violence are more likely to experience isolation and feelings of self-blame (Herman 16, 68). These reactions are shaped in part by dominant cultural discourses about sexual harassment and assault that interrogate survivors about their own behaviour before, during, and after the violence they've experienced. Internalizing these harmful messages can lead survivors to minimize the violence they've experienced ("it couldn't have been that bad") and to avoid disclosing their trauma to anyone in their community ("no one will believe me anyway"). These are strategies of self-preservation within a culture that investigates, with undue scrutiny, the credibility of those who report sexual violence. Trauma, then, is inflicted both by the perpetrators of the initial harm as well as by cultural actors at all levels who contribute, out of ignorance, discomfort, or malice to an atmosphere in which survivors are silenced and overlooked. On this, Maurice E. Stevens writes, "the symptom or the trace of the event or agents of injury acts as a kind of memorial to what Peter Shabad calls 'one's lonely suffering,' the failure of the surround to hold, more than it does the event itself' (27). 
Integrating trauma

As a person who lives with sexual trauma I am cautious about using language that indicates or promises any recovery from that trauma - allusions to "putting it behind you" or "healing" have never felt helpful or realistic to me personally, so I avoid that type of rhetoric here, although, of course, any reader's needs may be different. I prefer instead to speak and write about moving forward with, and in, trauma. Susan Brison, a philosopher and survivor of attempted sexual murder, writes at length about the process of integrating the trauma into the self. She credits a variety of methods for her eventual ability to reconfigure her life after the assault she experienced: medication, self-defence classes, pursuing justice through the court system, and therapy, but she places the heaviest emphasis on the restorative benefits she found in telling and retelling the story of what happened to her to listeners who were willing and able to hold that history with her. Brison writes that, "This working through, or remastering of, the traumatic memory involves going from being the medium of someone else's (the torturer's) speech to being the subject of one's own" (Aftermath 15). While Brison writes at length about the powers of language and speech (some of her retellings occurred through writing) she offers no insight as to what roles tone or genre of communication may play in a survivor's experience of testifying to trauma, and instead relies on her readers to fill in the blanks with their assumptions. This neglect contributes to limiting our collective understanding of the affective range survivors of sexual violence use while expressing themselves since many would assume that these conversations would be of an emotionally heavy and confessional nature. What, then, of those of us who laugh sometimes? Who find willing audiences by inviting them to hear our jokes? It is into this slight splinter in Brison's otherwise thoroughly compelling work that I insert my project and wedge open a space for introducing the subjects who laugh together in, with, and at trauma. 


\section{CHAPTER 2: Methodology}

Overview

I relied on a variety of research methods and methodologies in the process of generating data for this project. The bulk of the analysis is based on seven informal in-depth interviews I conducted with survivors of sexual violence who have performed stand-up comedy about rape and rape culture in Canada; they are referred to throughout the following chapters by the pseudonyms Victoria, Lisa, Avery, Nancy, Katie, Simone, and David. I retain ownership over the transcriptions from each interview. Portions of two stand-up comedy sets written and performed by Jordan Ross and Mayer, who also meet the above criteria, supplement the interview material. Both of these sets were performed in front of crowds of survivors and our allies, were marketed explicitly as comedy by survivors about sexual violence, and are available for viewing on YouTube. I engage with the interview and comedy performance transcriptions through a combination of discourse analysis and cultural analysis. These methods allow me to both consider the nuances of the language my participants used when engaging in or talking about comedy about sexual violence, and to study the social and cultural implications of those comedic performances themselves. Feminist post-structuralist discourse analysis and standpoint theory served as the methodological foundation for my use of the above methods.

\section{Recruitment}

The recruitment model I used for the interviews was based on recommendations made in Rebecca Campbell and Adrienne E. Adams’s 2009 work, “Why Do Rape Survivors Volunteer for Face-to-Face Interviews? A Meta-Study of Victims' Reasons for and Concerns About Research Participation." They found four principal reasons why women survivors of rape volunteered to participate in interviews with them: a desire to help other survivors; a desire to help themselves; the importance and value of research; and a need for money. Knowledge of 
these motives, though not universally applicable, was instrumental in helping me craft both my recruitment posters and the recruitment emails I circulated to institutions and people across Canada. I initiated contact with national and local comedy venues; educational institutions with comedy writing-based curricula; and producers of feminist comedy festivals, with requests for them each to circulate my information through their networks of practicing or former stand-up comics. Comics who had previously performed relevant material and who had public contact information were approached directly to participate. In my initial research design I planned on hosting the majority of my interviews in person. This execution shifted as I moved into the interview stage of my research and found that there were people outside of my locale who were interested in participating. I ultimately interviewed seven stand-up comics who had previously performed material on stage about their experiences of sexual trauma. Participants were located across southern Canada, with representation from both Atlantic and Pacific coastal provinces, Ontario, and Quebec, at the time they were interviewed. Interviews were conducted over phone, Skype, and in person and ran between 30 and 75 minutes each. They were scheduled between late August and the end of September 2016. Each participant received \$20 in compensation for their time. The suggestions Campbell and Adams make in their text were also effective for the interviews I hosted via phone and Skype.

Confidentiality

In the interest of respecting the privacy of all participants I only collected very limited demographic data from the people I interviewed. Although they will each be referred to by pseudonyms in this text, I wanted to ensure I used the appropriate pronouns when referring to each person, so gender information was requested and provided by most participants. More extensive demographic data was deemed unnecessary at the start of the project, but upon 
reflection I understand that its collection could have contributed to a more multi-faceted analysis, particularly regarding the intersections of race, class, age, and ability as they relate to sexual violence and comedic styles.

Professional stand-up comedy is a tough business for anyone to enter, but, as in wider Canadian culture, some people face greater challenges than others due to systemic racism, transphobia, sexism, ableism, ageism, and other injustices. People who experience physical, mental, or emotional symptoms of trauma may find it challenging to participate in a comedy scene even if they do have a genuine interest in doing so. The low- or non-paying status of most comedy gigs for amateur or semi-professional comics is also a barrier to entry for people who cannot spare their time or energy on projects that don't lead to compensation. Straight white cisgender men are still the largest demographic in Canadian comedy, disproportionately filling slates and employed as producers and club owners while comics of colour, Indigenous performers, comedians from the LGBTQ community, and women comics are often relegated to specialty "themed" shows about their identities, and are rarely able to break into the mainstream industry. On top of this, many comedy clubs are inaccessible to people who use mobility devices, while shows typically start late in the evening, often on weekdays, creating a temporal barrier for people who do shift work or who have children or other dependents. These points of consideration are not taken up in this project, but I point to them here to encourage future scholars and practitioners to consider them as potential avenues of research and critique. Interviewing

In addition to their work on recruitment practices with women survivors of sexual violence, Campbell and Adams worked with Sharon M. Wasco, Courtney E. Ehrens, and Tracy Sefl to conduct additional methodological research with the same population. Their article, 
“Training Interviewers for Research on Sexual Violence: A Qualitative Study of Rape Survivors' Recommendations for Interview Practice," presents data generated through interviews with survivors about their preferences for and opinions about their experience of being interviewed about their histories of rape. They found that the people they spoke with focused on four main issues: that survivors of rape are diverse both in their identities, experiences of violence, and emotional reactions to that violence; that what they term "recovery" is a continuous process and that each survivor will have a different relationship to their assault; that interviewers cannot truly understand a survivor's perspective unless they are survivors themselves; and that interviewers should use these knowledges to create safe, comfortable environments in which survivors can have someone bear witness to their story with compassion (604).

The aforementioned article is also useful due to the transparency with which the authors outline their own process of training interviewers. They emphasized several key expectations for each interviewer to fulfill: prioritizing the emotional well-being of each survivor; giving each survivor the time to tell their own story in their own words; demonstrating patience and respect; encouraging survivors to ask questions of the interviewer; providing information to each survivor that would normalize their experiences; and maintaining an atmosphere of warmth, compassion, and understanding (601). My previous and ongoing work supporting people living with sexual trauma has allowed me to develop several of the above skills, so I felt confident in practicing them here. I found a challenge in adjusting my role from being an active listener and resource and referral provider to guiding the conversation and requesting particular information from the participants. The Campbell, Adams, et. al. piece helped mitigate my anxieties about coming across as a prying researcher by offering the perspective that, "Interviewers listen to document 
someone's story, and if this can be with engagement and empathy, then survivors might receive something very useful from the experience" (607).

The amount that each interview focused on actual experiences of violence varied by participant - some were candid about the details of the sexual trauma they carried, while others chose not to volunteer that information. No participants were prompted, either directly or indirectly, to disclose any element of the violence they had lived, but I met any such disclosures with compassion and by matching my tone to theirs. Several participants asked about my own motives for pursuing this project, and, in accordance with Campbell, Adams, et. al.'s recommendations, each time I spoke succinctly to my own status as someone who lives with sexual trauma ("Training" 601).

These texts offered key considerations for me as I planned and performed the interview stage of my research. The consultations with survivors of sexual violence these researchers accomplished, although far from exhaustive, demonstrate a commitment to ethical feminist research practices that centre, respect, and value the lived realities of participants, a tradition to which I want my own work to contribute.

Feminist methods

A major tenet of feminist research practices is reflexivity - how do we, as researchers, fit in or influence the findings that we share? All research is culturally and politically bound; feminist self-reflexivity encourages writing these boundaries and biases into the text to allow readers as transparent a view of the research creation as possible. I model my approach after work on sexual violence by writers like Brison, Linda Alcoff, and Laura Gray, as well as after Campbell's research teams referenced above. These authors refer to their own respective experiences as survivors of sexual violence and/or as women within rape culture as valid points 
of inquiry and knowledge creation. I appreciate how this tactic establishes women's experiences as generating valuable academic work at the same time as it offers readers insight into the cognitive and emotional labour behind studying sexual violence and trauma.

Feminist research methods are also characterized by their "emancipatory knowledge interest," as Mats Alvesson and Kaj Sköldberg write in their book, Reflexive Methodology: New Vistas for Qualitative Research. Feminism is a political position as well as a theoretical framework, an association that compels its academic subscribers to consider how our work can be applied outside of a scholarly context. In her book Feminism is For Everybody bell hooks praises the consciousness-raising work of early feminist scholars who fought to have women's writing, perspectives, and accomplishments recognized and valued within higher education. But, she argues, this was followed by a separation of feminist thought from feminist practice: "Feminist theory began to be housed in an academic ghetto with little connection to a world outside. Work was and is produced in the academy that is oftentimes visionary, but these insights rarely reach many people. As a consequence the academization of feminist thought in this manner undermines feminist movement by depoliticization" (22). This insularity is achieved, and can therefore be resisted, as much through writing style as publication medium. I consider the anti-rape comedy referenced throughout this thesis as attempts at incorporating feminist politics into a wider public practice.

Feminist post-structuralist discourse analysis is a relatively new development within the field of discourse analysis. It branches off from critical discourse analysis in a few key ways. Where critical discourse analysis has tended to place subjects of inquiry in opposition to each other based on their relative power positions, feminist post-structuralist discourse analysis grapples more seriously with the complexity of power dynamics (Baxter, "Feminist" 3 ). This is 
grounded in Foucault's conception of power not as a stable element any subject or class can "have," but rather as a system that is constantly in negotiation (Foucault, History 95). This opens up space for considering how people can both wield power against others while simultaneously being subjected to domination. This point is especially poignant here since I am not conducting a straightforward analysis of gender dynamics: both men and women survivors are included as interview participants, and the recorded sets to which I refer have been performed by one man and one woman comic. A post-structuralist perspective allows me to move away from a maleaggressor female-victim dichotomy towards a more nuanced understanding of the interplay between gender and sexual violence. Another point of divergence from critical discourse analysis is in feminist post-structuralist discourse analysis's stance on materialism. While the former asserts that discourse is shaped by and continuously reconstructs material reality, the latter takes an anti-materialist position, also in line with Foucault, by arguing that there is no social reality outside of discourse (Baxter, "Feminist" 3). In other words, there is no way of absorbing or communicating pure information about the world since language is fed through systems of culturally and historically bound discourses. Critical discourse analysis and feminist poststructuralist discourse analysis share some theoretical foundations, including the perspectives that discourses are often interwoven with each other; that meaning is context-specific; that identity, following Judith Butler's work on gender, is performative; and that speakers have multiple and diverse identities, of which gender is only one (Baxter, "Feminist" 2). Judith Baxter's work using feminist post-structuralist discourse analysis as a research method has taken up speech as a site of investigation when used interactively - in conversation with others (Positioning). My own analysis is based on one-on-one interviews and one-to-many performance segments and so loses the emphasis on direct discursive interaction. I ground my work in the 
theoretical tenets Baxter outlines and focus instead on how each interview participant locates themselves within particular discourses on gender and violence and how their attention to language in their own practices of cultural production contribute to counter-discourses of feminist resistance.

The central principle of feminist standpoint theory is that marginalized people have more of an opportunity to perceive objective truths about the world because they exist in a different relation to the structures of power that privilege the dominant classes (Rolin 218). This claim relies on the argument that people who benefit from systemic privileges are, consciously or not, partial to their positions of domination and are therefore unwilling or unable to objectively critique the structures that support their place in the status quo. More marginalized people are less likely to experience a sense of allegiance to these power structures and would be more able to accurately testify to their repressive and oppressive machinations (Rolin 218). This methodology operates from the perspective that knowledge is both contextual and dynamic; in other words, standpoint theories recognize that knowledge is developed from observing and critiquing features of our real world, and that the process of generating knowledge necessarily impacts our understandings of the world we seek to know, which requires researchers to be attentive to the shifting issues at stake in our investigations (Rouse 201, 207). Finally, this methodology refuses the distinction between science and politics and argues that, in many cases, good science and feminist politics support and stimulate each other (Harding 30). I honour the voices and experiences of the survivors who participated in my research by adopting methodologies that privilege their knowledge contributions. 
CHAPTER 3: Culture and comedy

Discourses of rape culture

Sexual violence is frequently represented in our mainstream media. News sources cover both ongoing and one-off stories of sexual assault and harassment, particularly about celebrities or politicians; Hollywood films rely on rape as a method of moving the plot forward or as a way to flesh out a character's backstory and motive; and television shows of all genres lean on sexual violence as a cultural touchstone. This chapter investigates the implications of these relentless depictions of violence and argues that the media focus on women as victims of sexual crimes contributes to the appalling real-life rates of sexual violence against women today.

In her book, Watching Rape: Film and Television in Postfeminist Culture, Sarah Projansky pores over dozens of contemporary and historical film and television texts to trace and critique the ways in which rape has been represented on our screens. She argues that, noticed to us or not, depictions of and references to rape are so popular that they pervade our everyday lives (2). This saturation becomes dangerous when representations are overwhelmingly encoded with similar themes and values. Depictions of women and children as victims of sexual violence take precedence over critiques of people who have perpetrated those abuses. An analysis of news coverage of rape in the United States revealed that headlines frequently rely on the passive voice when describing crimes perpetrated by men against women, a rhetorical tactic that guides the reader's focus towards the victimized woman (Fahs 65). Breanne Fahs describes the cultural fascination with women rape victims as a fetishization of the submissive woman (65). This persistent focus on women as potential or actual targets of sexual violence limits the diversity of women's experiences portrayed onscreen: "The frequent appearance of 'rape victims' in television, legal, and social discourses also signals that women fall into a dichotomy wherein they are portrayed as rape victims to the exclusion of all other identities" (Fahs 65). Projansky's 
and Fahs' analysis illustrate how rape culture operates within mass media as both a cohesive and developing presence.

The "sustained definition of women as sexually victimized" circulated through mainstream media can inform how viewers understand and relate to real women in their social lives (Projansky 95). This ideological domination can even leak into how survivors of sexual assault interpret their own experiences. One participant, Lisa, referring to a comic whose set about sexual violence she witnessed, commented that, "One woman, this stayed with me, she was a journalist and in her head she referred to her own rape as her 'alleged rape' when she was talking to herself." This is but one example of how the dominant discourse seeps into everyday life to secure the stable reproduction of rape culture's values and meanings. This internalization of rape culture's values can become evident during actual moments of crisis as well as in someone's post-traumatic response. This joke from Jordan Ross exposes how, even during an attempted rape, she felt inclined to give her aggressor the benefit of the doubt:

Someone tried to rape me in high school and he had me pinned down, really big guy, and I was saying no, and I was like, “Oh my god, he can’t hear me saying no. His poor ears. Someone call an audiologist, stat! We need help."

With this bit she highlights how the tendency to justify and excuse sexually violent behaviour can dip into the realm of absurdity. Rather than calling for help for her own selfpreservation, Jordan Ross announces that help is needed for her attacker's ears - assuming that he must not be able to hear her resistance, because if he could then he would surely act in her best interest. Lines of reasoning that assume goodwill, while intentionally humorous here, are often used to minimize survivors' trauma responses by emphasizing the importance of intentionality on the part of the assailant. Proponents of rape culture advocate for people accused 
of sexual violence by arguing that they did not intend to cause harm; pro-survivor responses often point out that this lack of intent does not nullify any harm that nevertheless resulted from their actions. Jordan Ross's joke was told in the context of a comedy show by and for survivors and their allies. This environment, full of people who likely have a high degree of familiarity with the traps of rape culture, would have contributed to the success of the joke. Both this joke and Lisa's comment about the journalist-comic above reveal some of the tensions produced when survivors of sexual violence push up against the boundaries of rape culture.

We can understand these tensions and anxieties sparked by the circulation of dominant discourses about sexual violence in a nuanced way by considering the structure of feeling they produce. Projansky highlights this when she writes, "Discourses of rape are both productive and determinative. They are not simply narratives marketed for consumption in an entertainment context or 'talk' about real things. They are themselves functional, generative, formative, strategic, performative, and real" (2). In other words, discourses of rape play a significant role in rape culture's constant process of becoming a naturalized element of our social reality. One participant, Victoria, commented on some resistance she encountered when producing a stand-up show about sexual violence in Halifax and made the connection between peoples' discursive practices and social behaviours:

We had one woman send us an email that was so weird. In Halifax. She was like, "I can't believe you're doing this show after what happened with the Parsons in Halifax," and I was like, "We're doing this show because of Rehtaeh Parsons, because we've got this toxic environment where we don't fucking talk about this stuff." People would rather vilify a survivor of rape than ever have to address that they let a shitty thing happen. 'Cause that's a whole community who failed her before what happened. She got raped, her whole 
community, one by one, failed her, and then she committed suicide. If you don't think that talking about it is what's going to solve that then you're delusional. Let's go back to never talking about this, we'll see how it works out. It was just really bizarre and I felt bad that somebody felt so hurt that way but generally, and I still believe this is true, survivors had never told us not to do this show. People worried for survivors, but survivors know, you're just going to grieve the way you grieve.

Victoria clearly articulated the link she observed between Halifax people's reluctance to speak openly about sexual violence and their failure to adequately care for Rehtaeh Parsons in the wake of the sexual attack and subsequent harassment she suffered from 2011-2013. Furthermore, Victoria emphasized that creating and circulating alternative pro-survivor discourses is a critical component of building a community's capacity to respond compassionately and effectively to trauma. Most of the participants I spoke with worked from the perspective that language and representation are part of, and thereby able to influence, culture, and, as media producers themselves, were deliberate in their efforts to dismantle and diversify the dominant discourses surrounding sexual violence that "naturalize rape's place in our everyday world, not only as real physical events but also as part of our fantasies, fears, desires, and consumptive practices" (Projansky 2).

Material domination of rape culture

The naturalized status of rape culture has social consequences for both survivors of sexual violence and their broader communities. Young women and girls can be particularly vulnerable to dominant discourses about rape, as they may come to understand themselves and their social locations by internalizing messages of victimization. Susan Brison introduces the language of pre- and postmemories to describe this process (Aftermath 88). She writes that, 
"Girls in our society are raised with so many cautionary tales about rape that, even if we are not assaulted in childhood, we enter womanhood freighted with postmemories of sexual violence. The postmemory of rape not only haunts the present... but also reaches into the future in the form of fear, a kind of prememory of what, at times, seems almost inevitable: one's own future experience of being raped" (Aftermath 88). The fear that Brison describes as "reaching into the future" is one that can influence, consciously or not, the ways that women shape their own lives. Lisa, describing the type of material she typically performs at mainstream shows, commented that, "In my stand-up I have some jokes about safety routines that women talk ourselves through and put ourselves through before going out at night or going on first dates." The knowledge of these routines, such as asking a friend to call at a specific time to check in on how a date is going, carrying pepper spray or a whistle, or making sleepover arrangements with a friend to avoid traveling alone late at night, is widespread among women - neither Lisa nor I sought to clarify which routines she meant, as we both, socialized as women, assumed the other was familiar with the practices despite being several years apart in age and living in different regions of the country. These safety practices can be understood as symptoms of the prememory of rape, ways in which our expectations of sexual violence structure how we choose which spaces to inhabit, and which people with whom we will engage.

The rhetoric of safety practices circulated among women and others hinges on the assumption that these practices work. Therefore, if one does end up as the victim of a sexual attack then they can be understood, from the perspective of rape culture, to have desired the interaction because, if they truly were resistant, then they would have enacted any one of those safeguards. This is a deliberate obscuring of how actual violence is likely to play out - attacks from strangers are statistically rare and women are seldom in a position to use pepper spray or 
have their keychain wrapped around their fist when confronted with violence by a previously trusted friend, lover, or spouse (Perreault). The myth of women desiring sexual aggression is reinforced by the mainstream media, as this participant, Nancy, described:

When you start talking about [sexual violence] you realise that you've got to have the rhetoric of why you feel entitled to not be raped. You have to have that on lockdown in order to feel strong enough to combat the clearly pervasive message that if you get raped it's your fault. That's still the stronger message out there. Even if we're getting to the point where we're not actively verbalizing, it's still at the end of the day in reality that's still how it plays out. When you see who gets support and who doesn't get support, when you see how people frame things in the media, "Oh this poor guy, his future is wrecked," versus, "This sultry college co-ed who was just walking around asking for it," you still see where the prevailing winds are blowing.

The language that we use to talk about sexual harassment and assault strikes a different tonal chord than the vocabulary we use when describing survivors of other mass offences. Brison argues that this rhetorical reduction serves to relegate occurrences of sexual violence as being either mere interpersonal disputes or random acts of violence, two frameworks that are divorced from any consideration of the systemic gender biases that permit the continued denigration of women: "We do not, generally, use the words 'testimony' or 'witnessing' in discussing rape narratives (unless we are speaking of courtroom scenarios). Holocaust survivors give their testimonies. Political prisoners bear witness to the torture they endured. Rape survivors tell their stories" (Brison, "Everyday" 192). The pairing of these dominant discourses, that women, in actuality, desire sexual aggression, and that sexual violence is disconnected from any larger cultural trend or ideology, can encourage survivors to question the validity of their own 
experiences. Similar to the comic/journalist who referred to her own rape as her "alleged rape," one participant, Simone, referred to a colleague of hers who was unsure if her experience of sexual abuse was severe enough to qualify her to perform at a stand-up show about sexual violence:

One of the girls that was in the show with me, she was not raped, she was sexually molested as a kid and she was like, "I feel like I don't belong in this show because it's [about rape] and I was never actually raped," and that was how she sort of started her whole joke, was like, “Mine’s not as bad, mine’s a G-rating and these guys are like rated R.” I was like, “That's really funny!" That wasn't even originally going to be her material, that was just her saying to us, "I feel like I don't belong," and us saying, "What! That's kind of hilarious, that should be a joke.

The stratification of categories of sexual violence serves rape culture's end of narrowing the field of experiences about which survivors can field legitimate complaints. These manufactured hierarchies of violence influence our understanding of trauma and impact the kinds of care available to people as well as the types of support they feel entitled to access. The economic inaccessibility of support services can also impact how survivors relate to their own experiences. Jordan Ross jokes about how changes in her employment status helped her come to terms with understanding that she had been raped:

When I was sexually assaulted I was too broke and too busy to be a survivor, you know? I was a part-time fishmonger and a part-time waitress and I was doing open mics four nights a week. So I left his house that morning and I was like, [to herself] "We're going to talk this one down." And then I got a better job, and then I got better at comedy, and one day I think I sat down and I had, like, guacamole and sweet potato fries in the same meal, and 
my body was like, [smacks herself in the head] "I was raped! You can afford the therapy now, you're free!" Which I appreciate my body doing, right, because I needed the time. But it would have been easier like, after it happened.

In this joke Jordan Ross describes how she minimized her own experience of violence as a method of self-preservation until she felt financially secure enough to seek further care. In this way an internal reduction of violence can function as a temporary defense mechanism for survivors. Trauma theorists agree that attaining a reasonable level of safety is an essential first step before a survivor can positively move forward after a traumatic experience (Herman 155). Safety is of course relative and can be a significantly more difficult status for people to attain if they are experiencing ongoing violence, especially if that violence is located in the home. Research into domestic violence has encouraged trauma theorists to broaden the scope of their analyses, since the historical definition of trauma as the occurrence of a destabilizing event outside the range of typical human experience fails to take into consideration the naturalized status of gender-based violence (Cvetkovich 32). Building on language proposed by Laura Brown, Ann Cvetokovich works with an understanding of both "insidious" trauma as well as trauma directly related to one punctual event (32). Both of these understandings of trauma are useful here.

These last several paragraphs have argued that insidious trauma can be partially discursive in form, illustrated by how rape culture reifies itself through language and representation. From this angle, where we witness the effort required to maintain a cohesive, everyday façade to rape culture, we can also pinpoint where we may be able to chip away at it: "Once the causes of trauma become more diffuse, so too do the cures, opening up the need to change social structures more broadly rather than just fix individual people" (Cvetkovich 33). Clinical psychiatrist and 
trauma theorist Judith Lewis Herman also suggests that an integral part of recovery, as she terms it, occurs for a "significant minority" of survivors of sexual violence when they begin to engage in social action (207). She refers directly to politics and religion as spheres on which survivors choose to focus their efforts, but, following Cvetkovich, I push for the inclusion here of cultural endeavours as another arena available to survivors interested in a more diffuse therapeutic process that pursues social as well as personal change.

\section{Counter-discourses}

This has long been the feminist tradition - to write women's voices and lives into the largely male canon of art and history. Feminist thinkers understood the urgency with which these projects must be undertaken and the connection women's writing had with women's social realities. In the very first lines of her Laugh of the Medusa Hélène Cixous declares that "Woman must write her self: must write about women and bring women to writing, from which they have been driven away as violently as from their bodies - for the same reasons, by the same law, with the same fatal goal" (245). This principle stands for the stories of survivors of sexual violence, although of course the gender divide is blurrier with this topic. Our mainstream media sphere still prefers content and perspectives that benefit rape culture, although pro-survivor and feminist journalists and artists are steadily gaining ground with their own interventions. If emancipatory content is desired, then, we must develop it ourselves or support those in our communities who do. Lisa credited her consumption of feminist writing as a coping mechanism after the violence she experienced as a young person:

I was assaulted when I was twelve, in grade seven, so it took a long time for me to understand what had happened to me, and I think I danced around it a lot. I read a lot, I read a lot of feminist writers when I was pretty young, at fourteen or fifteen. I was always 
an avid reader. The interest in, "I wanna read a Gloria Steinem book!" in the '90s was like, "Huh?” It didn't come from my mother or any women in my life, so I think that was how, for a long time, how I sought out support or understanding.

Writing by marginalized peoples can so often be a site of refuge from a wider, more hostile culture. Survivors must be supported to "create histories that feature themselves and their loved ones as vindicated whole beings who possess the stuff of historical merit - will, selfawareness, culture, humanity, and so on" (Stevens 20). Diversity of narrative and experience is a strength. Just as it is critical to produce discourses of joy in which we can find hope and serenity, it is also important to find the language to represent struggle, trauma, and pain.

Writing pain is a challenge. As a purely individual experience, "there is no language for pain... it resists verbal objectification" (Scarry 12). But if cultural products, as Stevens writes, are loci for "memory management," grappling with pain's resistance to being communicated clearly is an essential project in keeping trauma real (20). Literary scholar Leigh Gilmore offers autobiographical writing as one site where survivors of trauma can practice bringing their memories into language. She argues that post-traumatic writing pushes the boundaries of autobiography and compels the genre to reckon with different understandings of memory, truth, and testimony (19). I would argue that stand-up comedy picks up this thread of Gilmore's thinking: comics who perform in personal or confessional registers indulge audience assumptions that their jokes are based, at least in part, off some lived reality. Katie commented on the ambiguity between her on- and off-stage personas in this way:

Stand-up isn't real and when I'm on stage I'm a character. I like to consider myself on stage as the best version of myself. Not a character, necessarily, like I just said I was a 
character, but it's not real. That person does exist within me, but that person isn't me all the time.

Conceptions of performativity are blurred for both performers and audience members alike. Assumptions of truthfulness are therefore present for comics as well as for writers of autobiographies, but the tendency to police comics' testimonies is much less rigorous. In her analysis of autobiographical fiction, Meg Jensen claims that while forcing a survivor of trauma into rigid fact-based requirements of truth serves to fix the author into a position of victimhood, "fictive forms allow that subject position to be continually re-negotiated" (439). Jensen and Gilmore both highlight how flexible approaches to truth-telling can serve survivors as we practice post-traumatic self-representation, while autobiographical genres that rely on strict definitions of truth exclude the voices of many survivors of trauma. Without these cultural texts to provide a historical record of violence, the stories and voices of survivors will be lost and abuses of power will continue unchecked. In her work on torture Elaine Scarry insists that the silencing of people's pain always allows mechanisms of violence to remain quietly in operation it is when pain is loudly announced that we can trace the pathways of power from wound to aggressor and begin to work in earnest to prevent further damage (Fahs 69). Brison repeats this imperative within the specific context of sexual violence, asserting that individual and cultural "recovery," as she terms it, requires a wide-scale witnessing of survivors' testimonies (Aftermath 58). The cultural importance of this witnessing is born from how easy it is to overlook pain, particularly traumatic emotional or psychic pain that leaves no marks on the body, no broken skin or bones to elicit sympathy or care. It is simple for those who have not experienced sexual violence to live as though no one has, since its implications and effects are, so often, private and invisible. This tendency to overlook can, in itself, be understood to cause further harm to people 
living with trauma - not only living with the aftermath of violence, but living in an environment that pretends that that violence does not exist (and wouldn't be a big deal even if it did) (Scarry 56). Brison therefore stresses the perspective not of learning about sexual trauma, but of unlearning the assumed absence of trauma from those around us (Aftermath 58). The project of unlearning hegemonic ideologies about sexual violence can influence how we understand our own personal experiences as well. Lisa spoke to me about conversations she had with audience members after her performance:

It's really corny but at the end of the show it was really nice to have people come up to me, a few women were like, "Hey, can I give you a hug?" 'Cause people identified as survivors or said that my experience specifically spoke to them. I had a few Facebook messages later too, and that had never happened to me before. So that was, from a selfish perspective, immensely gratifying, because one of the reasons, the main reason I like comedy, or what I want to do with my comedy is reflect peoples' experiences back to them and give a voice to that. I guess it's kind of selfish, it was nice to finally be able to do that.

Several participants described having similar interactions with audience members who expressed gratitude for having recognized themselves in the content the comics had performed. The successful articulation of pain not only establishes a history of violence that has past, but works to weave survivors together in the present. Locating these relationships between survivors in the present reminds us of the aliveness of Williams's structure of feeling - not relegated to systems and institutions that have been founded and cemented in the past, cultural and artistic texts are able to glide fluidly through the present-tense, flexing and morphing to suit current needs and styles (Marxism 133). This is the privilege of art - to exist somewhere between systems of meaning, to skirt at their boundaries and, when executed skilfully, to encourage new 
ways of feeling and nurture new social experiences (Williams, Marxism 133). The arts, broadly speaking, are useful also in their diversity and accessibility. As I stress the importance of women's self-representations and the representations produced by survivors of sexual violence, I see those efforts in a variety of forms and genres: television episodes; novels; memoirs; video games; Twitter essays; short or feature-length films; stand-up comedy. Divisions of taste or class may lead each of us to different sources or sites for the art we chase, but those divisions shouldn't restrict any of us to worlds where our lives are not represented. Speaking to her experiences performing feminist material at mainstream comedy shows, Victoria explained that: I especially tell those jokes after particularly egregious performers, because you can sense women tensing up in an audience thinking, "I'm never going to a comedy show again." I've seen that happen so many times, that a guy goes up, or a girl, it's not a gendered thing, tells these shitty jokes and you see women in the audience, you see their stomachs flip and go, "Well, turns out I hate comedy.” And I just think that's so sad because comedy's so diverse, it's so much more than that. So I go up and tell those jokes and say, "Look, someone's on your side." And then I do get that support.

To represent pain through art is to reflect survivors' experiences back at us in ways that make us feel visible, respected, and real in a world where we are so often told otherwise. These representations can help us build connections among each other and, through hearing each others' stories, we can come to counter rape culture's power over us by learning to remaster our traumas and resist further impositions.

Perspectives on representing trauma

Recent cultural inquiries into trauma have prodded with curiosity at the links between trauma and performance. The following sections will explore these links and argue that stand-up 
comedy can function as an effective performance exercise for survivors who are looking to work with their trauma in the cultural sphere. It is critical to remember that a survivor's body is always also the body of evidence; the body that stands onstage is the body that has withstood violence. I return to the suggestion I offered earlier: scholars intrigued by the tensions and links between trauma, performance, and the body will find a wealthy resource in investigations into survivors and stand-up comedy. I attend to questions of the embodied nature of trauma only briefly in the following chapters as the scope of this project is intently focused on discursive, primarily verbal, representations of trauma and sexual violence.

From a psychoanalytic/psychotherapeutic perspective, trauma symptoms can be understood as performative, in that people who live with trauma can be seen to "'act out' compulsive repetition of actions, words, and situations from traumatic occurrences" (Duggan 5). These conscious or unconscious intrusions of traumatic memory into present-day life establish trauma's lingering presence in survivors' lives. Testimonials from survivors, and evidence from clinical practitioners who work with survivors, suggest that it is through the conscious repetition and reworking of traumatic memory that the intrusive and unwanted symptoms of trauma begin to abate (Herman 3; Brison, "Everyday" 190). Performance theorists and artists have taken up this focus on repetition to suggest that theatre and live art offer valuable context and structure for survivors' self-representation (Duggan 5). This move plays into Cvetkovich's argument that trauma calls for "an unusual archive, whose materials, in pointing to trauma's ephemerality, are themselves frequently ephemeral" (7). She cites testimony and performance as modes of expression disentangled from dominant expectations of archival permanency yet still able to leave a cultural residue indicating that we were here, and this happened to us (7). Stand-up comedy, as a genre of ephemeral yet repeatable performance, satisfies both of these calls. 
Survivors are recognizing that these elements, combined with the particular linguistic, cognitive, and affective creativity humour requires, can foster practices of self-representation that facilitate trauma's integration with the laughing self.

Expanding the emotional archive

Some survivors find the affective breadth allowed by comedy to be a relief from the social pressures of everyday life. In her work on the Nazi Holocaust Cvetkovich introduces the term "emotional archive" to describe the range of feelings associated with trauma (23). She writes that, "responses to trauma are often constrained by (normalizing) demands for appropriate affects" (26). The emotional archive available to survivors of sexual violence is limited. These confines are produced largely through the proliferation of mainstream discourses about sexual violence that deny survivors' authority over their own experiences and lock them into positions of victimhood, as illustrated here in chapter 3 (Alcoff and Gray 277). Television programs, magazines, and other media sources profit from easily digestible dramatic narratives. These rely on simple affective trajectories with legalistic approaches to truth-telling either leading upwards from ruination to recovery in the case of inspirational stories, or descending into depression, selfharm, substance abuse, or suicide in the case of tragedies (Gilmore 3). Experiences outside of these parameters are rarely included (Alcoff and Gray 277; Projansky 2; Fahs 65). One of humour's gifts is the permission it grants for survivors to express feelings or opinions that would otherwise be considered inappropriate or socially unacceptable, contributing to the expansion of the emotional archive of trauma (Meyer 318; Cvetkovich 23). Victoria recounted how she pokes fun at the affective limitations imposed on survivors of sexual violence, responding in particular to claims that survivors are too easily offended and should stay out of comedy spaces: 
I say as well, 'I get it, I get it, if you're sensitive, don't come out to a show. Because why should someone who's had this worst thing to ever happen to them ever deserve to laugh again?" Just these absurd rules that people have for survivors.

Allegations that survivors are too emotionally sensitive to withstand the potential risks of a comedy show have their roots in these same mainstream discourses. In actuality, survivors are entering these spaces to engage directly with those risks as comedy producers and performers. They're working to expand the emotional archive of trauma by demonstrating that pain and laughter are not mutually exclusive. What Victoria, quoted above, makes clear is that the "absurd rules" demanding appropriate affect from survivors are imposed by people who are not themselves survivors of sexual violence. Even when speaking about their own personal trauma, survivors are socially required to cater their affective demeanour to non-survivors. Comedy is a space where many, though not all, of these requirements can be lifted. Another participant, Simone, replied that since performing stand-up comedy about her sexual trauma she had learned, That you can laugh about it, first of all. Every time you want to talk about it with a friend it always feels so dire. Your friend is like, "We need wine now!" It felt so intense.

A third participant, David, explained the different tones he takes when talking about sexual trauma on stage versus off:

Sometimes. Yeah. Sometimes I have to tone it down a little bit with people because they think it's something you shouldn't joke around about. Casual conversation can make it very awkward if I talk about it the way I normally do on stage.

In David's experience comedy was a space where he could transcend the restraints of social convention to practice a different affective relationship with his trauma (Billig 208). Still, comics are performers and must be mindful how their material is landing with their audience. 
Victoria, who agreed that comedy allowed her the space to represent her trauma in more diverse ways than people allowed in everyday life, reflected that she still felt some pressure to cater to her audiences:

One thing that was tough to reconcile was how angry I am, and how people don't like that I'm angry. People in the audience don't generally like that I'm angry, and so I had to find a way to express my anger that was palatable to the audience, which was so weird.

Comedy is not a cure-all for survivors struggling with discursive limitations. What it offers is a site where many social conventions are suspended, where survivors can experiment with new or different affective self-representations and practice re-negotiating their subject positions through a more flexible approach to autobiography, and where non-survivors can learn that disclosures of trauma are not inherently awkward or dire - that the emotional archive of trauma is stocked with hidden, complicated, and revolutionary resources. Mechanism of resisting interpellation Rape culture maintains its dominance, in part, by propagating narrow codes of subjectivity. Survivors are easier to define, and discredit, when we are uniform. Binding us to the label "victim" ties us also to the acts of violence we have withstood: we come to be defined not by our own lives or actions, but the actions of others. Victims are also gendered, in mainstream discourses, as women (or children of any gender). Adult men are often doubted when they disclose sexual violence, especially if they report being forced into penetrative vaginal sex. This sets up a dichotomy in which all women are actual or potential victims, and all men are actual or potential aggressors (Cox 980). Part of any struggle against rape culture must seek to dismantle this arrangement. One lens through which this challenge can be considered is Louis Althusser's theory of interpellation. With this, Althusser seeks to explain the relationships between language, 
power, and the socially constituted self, or subject. He contends that humans come to be social subjects through a process of recognition, or 'hailing.' We may be hailed directly by other subjects, as in Althusser's famous example of the policeman shouting "Hey, you there!" on a busy street and the person in question turning to look, or, more generally, through the mass media. Judith Butler writes, "it is by being interpellated within the terms of language that a certain social existence of the body first becomes possible" (Excitable 5). In other words, it is through the process of interpellation that we come to be recognized and recognize ourselves as gendered subjects falling on either side of the victim/aggressor line. The question then arises - is there a method of resisting interpellation? I follow Parveluscu's line of thinking here in suggesting that laughter may be able to play such a role. She concedes to Althusser that hailing is always at least in part successful, but argues "the laughing yes that returns pushes the play of affirmation and negativity to new levels of ambiguity. It is no surprise that the subject produced or confirmed in the acoustic mirror of this hailing will laugh again" (70). If the act of recognition is also the act of constitution, introducing an element of ambiguity to the scene muddles both how other subjects recognize us and how we understand our own selves as social subjects (Butler, Excitable 25). Practicing a laughing response to language that calls us into being as subjects within rape culture is one way of startling that culture into reconsideration. 
CHAPTER 4: Experience of the performer

Working through trauma in language

Survivors work in a variety of ways to manage the symptoms of our traumas. This chapter takes up the social and affective experiences of survivors who accomplish stand-up comedy performances about living with sexual trauma. For now I leave aside questions about what drove these comics to integrate this material into their sets, although future researchers may find that avenue quite fruitful for proposing systems of supporting other survivors interested in attempting comedy performances of their own. All but one of the comics I spoke with had accessed some type of support service, either therapy or a community-led crisis intervention program, to help them manage their experience of trauma. This trend again points towards the necessity of pluralizing our cultural understanding of how people move forward after sexual violence. A variety of clinical services are currently available for those with the time and financial means to access them, and many survivors do find relief and release by pursuing such a medical approach to trauma management. A cultural perspective on trauma, however, inspires suspicion of the assumption that these diagnostic approaches are always preferable to sociocultural interventions (Cvetkovich 10). Cultural initiatives, used alone or in conjunction with medical treatment, can work to reduce dissonance between survivors' internal experiences of trauma and social environments that frequently discount those experiences offhand. Distinctions in language are necessary in order to avoid conflating these approaches - Wendy Bishop suggests the descriptor "therapeutic process" rather than "therapy" when writing about cultural practices that help people work through trauma, a choice in language that I will also adopt here (Bishop).

Trauma operates, on one level, to disintegrate the survivor's perspective of themselves as a subject of their own narrative. Since trauma, either as an isolated (punctual) event or as a series 
of insidious events, forces the survivor to understand their life as happening outside of their control, it can be a wildly disorientating experience for people who, naturally, had presumptions about the ways in which their lives would unfold. Sexual violence, as a human-imposed trauma, dislocates the survivor from the position of narrator and relegates them to being objects of someone else's actions within their own life story (Jackson 209). This also has implications on survivors' memories; frequently incapable of remembering the traumatic events in a controlled or linear fashion, survivors are often instead subjected to unwanted repetitions of those events in the form of intrusive memories, flashbacks, or nightmares (Wicks 135; van der Kolk S98). This is where a cultural approach to trauma can be useful - reconceptualising one's traumatic experiences into coherent narratives in which the survivor is the subject of their own story can be part of a valuable therapeutic process.

Stand-up comedy, outside of one-liners and experimental tactics, requires that the performer write cohesive mini-narratives, in the form of bits, or more extended narratives for comics who work in a storytelling format. The writing process for survivors of sexual violence who are crafting jokes about trauma, therefore, necessitates a conscious revisiting of traumatic memories. Several participants described the process of writing material about sexual violence as being emotionally challenging. Lisa described her process in this way:

[The writing process was] pretty brutal. It was in very small spurts... There was a resistance to the permanency of putting things on paper... I definitely didn't sit down for an afternoon and write. Even when I was writing I would write and then be like [howl] and slam a book and throw it or something, like very sort of ridiculous.

And Simone commented that, 
The [writing] process was awful, I have to say. It was kind of like, things that I had, not buried, 'cause like I' $m$ in therapy, and I felt like we had dealt with it and put it in a little box and put it away, and then I had to open that box up again and I found that really hard. I drank a lot of wine. Probably not healthy, but yeah. During the writing process I would have a couple glasses of wine and write things.

Finally, Nancy offered her thoughts:

When you work on this you're really working through what... you're really contextualizing your assault. It hurts. But it's so good to root it out and say, "Okay, what does this mean to me, what does this mean to the greater world, and what's my stance on this?" It's really so heavy. It's so hard to do but it's so heartening to work through. Nancy there made a connection between the writing process and feeling a change in her relationship with her traumatic past. She also pointed towards her impulse to craft a narrative that was in some ways representative of other survivors as well as of her own experiences. Lisa and Simone focused here on the difficulties of the writing process but were later emphatic about how emotionally satisfying the eventual performance of that material ended up being. Each participant reported some positive aspects of writing and performing their set, although the timing, type, and degree of benefits varied from participant to participant. The psychic toll of rooting out and writing up past traumas can be considerable since survivors aren't simply reexamining past events; the writing process entails a transformation of fragmented memory into intelligible anecdotes that an audience of strangers can follow. The translation from memory to text is an act of recuperation, as the narrative that is ultimately produced has taken events that initially occurred beyond language and recovered them into language (Wicks 135). This reconceptualization is an active process alive with the potential to significantly change how 
survivors relate to their own memories: "saying something about a traumatic memory does something to it" (Brison, Aftermath 56). Since any narrativizing pursuit must begin with memory, this analysis has, until now, focused on writing as a genre-less task. But, of course, writing comedy about sexual violence entails a vastly different process for the author than writing about it using any other style.

Benefits of comedic principles

The cognitive and linguistic strategies necessary to joke writing encourage a therapeutic process for working through traumatic memory. The relief theory of humour describes laughter provoked in people who recognize that an aberration to an accepted norm has been rectified and life has returned to safety and normalcy. The key elements here are, sequentially, the recognition of an accepted norm, the aberration that induces anxiety, and the subsequent return to safety once the discomfort has been alleviated - this is the cycle of relief humour. The humour here hinges on peoples' desire to reduce dissonance between disparate elements or energies. We generally find awkwardness unpleasant to witness or experience and we tend to notice disruptions in expected patterns. These events can vary in intensity and might induce anything from cringing to outright panic as a response; the intensity of the conclusion of the cycle varies in turn and, with a well-executed joke, the relief felt by the release of tension should match the amount of anxiety initially provoked by the joke. The capability to elicit a feeling of release is my first point of interest in the therapeutic process of writing and performing comedy about sexual violence. It can be a real victory for survivors to craft a narrative of their own that follows the cycle of relief humour: identifying the existence of a pre-traumatized self, locating the source of trauma, and alleviating some discomfort by reconceptualising the situation. This type of narrative can make a "situation seem more elastic, or more manageable, by showing that difficulties are not so 
overwhelming as to be out of control after all" (Meyer 312). Avery provided an example of a joke he tells to mainstream audiences that demonstrates a successful attempt at reconceptualising the trauma of childhood molestation:

I was molested when I was a kid, when I was five I was molested a few times. One of my favourite jokes is, "I used to do really well for myself, back in the day I used to pick up left and right as far as like, it's a dude a day, you know, but then I turned seven.” That usually goes over alright, people tend to like that.

This joke effectively identifies the desirable social norm of having an active and pleasurable sex life and then quickly contrasts it to the anxiety-inducing idea of applying that norm to very young children. Writing a joke like this might encourage "an internal redefining of sociocultural reality" that helps a survivor to understand their trauma not as a life-ending event but as an experience that can be incorporated into their new reality more easily (Meyer 311 ). The joke above, like many stand-up comedy bits, relies on an element of surprise to be successful: framing being molested in one's childhood as being successful at "picking up dudes" is an unexpected approach. This type of reworking traumatic memory requires remarkable cognitive labour. Another example of this humour at work is in the joke that Mayer uses to begin his set at a sexual violence-themed comedy show:

Before I get started I just want to mention something. I recently applied to be in the Winnipeg Comedy Festival, but I unfortunately didn't make the criteria so I didn't get into that show. And then I applied to be in Next Top Comic, and again unfortunately I didn't meet the criteria for that show, so I'd like to just quickly say thank you to my uncle for helping me meet the criteria for this show. 
Similarly to the joke above, Mayer's bit relies on a quick reframing of the situation to generate surprise and laughter. Conceptualizing his own childhood rape as beneficial to his existing career and thanking the uncle who raped him for propelling him to his current success is in complete opposition to how any listener would assume Mayer would relate to those events. Performing gratitude where one would expect malice or shame introduces an affective incongruity that contributes to the success of the joke. Not only does an author need to have developed a stable narrative of their trauma, they need to then hold that narrative in place and step back from it to consider it from different angles and affects in order to make new connections between elements they've previously considered disparate - such as in the examples above. This is where Jensen and Gilmore's work on autobiographical fiction becomes useful again: like the texts they present, stand-up comedy shifts the grounds of judgment away from strict definitions of honesty and rewards survivors like Mayer and Avery for their creative expressions of trauma and memory (Gilmore 143). Later in our interview, Avery acknowledged the cognitive labour involved with writing jokes about sexual violence:

For sure I'd like to say why I think it's important to write jokes in regards to it, just because it's one of the most cathartic things to do, when you experience trauma, is to flip it and laugh at it. I always believe that the whole world is a joke and it's either like, you laugh at it, or it's laughing at you.

Here he understands practicing shifting perspectives as "flipping" assumed conceptions on their heads in order to gain control and the ability to laugh at what had previously been considered upsetting. This experience is in line with Brison's assertion, referenced earlier, that saying something about a traumatic memory does something to that memory, but indicates that the manner in which something about the memory is said can influence what may happen to it 
(Aftermath 56). According to Avery, speaking humorously induces a more cathartic response from him than by speaking in any other mode. Humour's position within language grants it special permissions: where ordinary descriptive/logical language runs up against boundaries and redundancies, humour is able to fill in some blanks. When language fails to adequately represent traumas we have experienced, we turn to adjectives like "indescribable, unspeakable, or inexpressible" to attempt to communicate the intensity of those actions or feelings (Jackson 210). More playful modes of speech invite metaphors and incongruities to the stage, so to speak. Comedic bits have the liberty to breach established boundaries, typical directions of thought, and assumed connections between ideas to introduce novel interpretations, definitions, and possibilities, all by encouraging more creative uses of language than those typically found in straightforward dialogue.

The most notable difference between humour and regular speech is the singular response humour invites: laughter. A successful comic will be able to orchestrate a crowd of laughers in unison. Laughter is often described as being 'contagious,' but this is not strictly true: in the case of language-based humour, like most stand-up comedy, a person must follow and "get" the joke in order to really laugh. In other words, they must fulfill the conditions of being susceptible to humour; sitting in a room full of laughers does not usually suffice. Getting the joke requires that an audience member share a knowledge base or ideological perspective with the performer: any number of intra-group ethnic jokes can serve as an example here. Katie had this to say about the nature of laughter: "A lot of what laughter is is you recognizing that - 'That's funny, because me, too. Me, that, also, too." It is this ability to spontaneously identify a common value, understanding, or belief that allows us to think of laughter as a method of forming social groups. I will write further on this in the following section, but I indicate it here first to suggest that the 
laughter that originates from shared experiences of trauma and rape culture can function to validate a comic's (fragmented, dislocated, traumatized) memory. The naturalization of sexual violence in our culture encourages survivors of sexual violence to diminish our own experiences of trauma. Coupled with how trauma functions in the brain to fragment and dislocate memory, the act of remembering violence, and of convincing oneself that it was (and is still) real and meaningful can be a slippery one. Similarly to how "the invisible genome vouches for the validity of phenotype, or the effaced technologies of the photo argue the 'Fact' of its real representation," a burst of laughter opens the curtains to the piece of reality being mocked (Stevens 34). One participant, Lisa, who was concerned that the sexual violence that had been imposed on her body was not severe enough to warrant the trauma she felt, described the pleasure she experienced in being validated by the audience reaction she elicited during her performance at a show featuring survivors of sexual violence:

It was funny to get validated in that way and then to talk about that on stage, like I joked about it on stage, feeling like, "Oh but I wasn't like really raped," and then giving it like a movie rating, people were really laughing and relating to that, and then hearing that basically every survivor, no matter what had happened to us, felt that way.

Lisa understood the laughter of audience members as a result of their ability to relate to the material in her bit. She was able to connect with other survivors with similar histories of having their traumas minimized and transform the pain of their struggles against rape culture into pleasure "at the idea of disrupting the social order" (Billig 233). Stand-up comedy is one cultural arena in which these connections and pleasures can be generated and affirmed. 
Witnessed repetition of a stand-up set

Rape culture maintains its power, in part, by producing and circulating content that dismisses the prevalence and significance of sexual violence. Survivors of violence are particularly affected by this ideological domination since we are pressured by a variety of sources to remain silent about the traumas we have lived. Silence can be a tool of resiliency and self-preservation, but silence imposed on a survivor against their wishes can reinforce and further their trauma (Schwab 120). Breaking their silence and speaking up about their experiences of violence can be transformative for a survivor if they find an appropriate audience and good timing to do so. Herman argues that the later stages of a survivor's growth process can only occur once the survivor in question finds such an audience and begins to speak about their trauma (3). She approaches this stage as one distinct from developing a cohesive narrative of one's own experiences and disentangling traumatic memories. For Herman, and other trauma specialists, the critical element of this step is reintegrating the survivor into a trustworthy social group (Herman 61; Brison, Aftermath 68). Because the stakes of any pre-existing relationships are nullified, some survivors may find it easier to speak to groups of strangers rather than close friends or family members about their histories of trauma (Payne 17). From this perspective, an unknown audience at a comedy club can temporarily assume the role of the listening community. Comedy shows marketed as feminist or survivor-centric often draw supportive, like-minded crowds. These audiences can rely on the conventions of the comedy club to fill in for the social scripts our culture still lacks for responding to disclosures of trauma and violence. Audience members are relieved from the position of having to individually respond to each performer's testimony and can instead assume group status. Comedy conventions encourage laughter, cheering, and applause after punch lines and at the end of each performer's set, validation for the 
comic who can interpret that their words have been heard and understood as they were intended (Brison, Aftermath 51). Victoria, who produced a recurring show featuring comics who had survived sexual violence, remarked on the overwhelmingly positive energy their audiences provided:

It went great. It was so amazing and it was really a combination of our efforts, which is very cliché to say, but we had an incredibly supportive audience. The audience was so supportive I was like, “Guys, this is a comedy show, fucking get it together.” It went incredibly well.

Simone described the atmosphere she felt while performing at a one-off sexual violencethemed show:

I felt so good about myself afterwards. As much as people tell you and you tell yourself that you didn't deserve it, you didn't do anything wrong, that voice is still always there, is still always telling you that you did do something wrong and you have to change your behaviour and act differently. I found after doing that show and just feeling that support and that love, I can't even explain it. It wasn't even the laughter and the applause, it was like there was a warm vibe the moment you stepped onto that stage you just felt like it was Christmas morning with your family, that really amazing, safe, warm space.

For David, gender factored into how welcome he felt while performing at a series of similar survivor-centric shows:

The shows I did, save for one or two, I was almost always the only male. The crowd, generally speaking, was not your Friday night or Saturday night Yuk Yuk's crowd. They were more of a social justice, feminist type. You could kind of feel a little bit each night that there was a bit of resistance by me just being there. 
Due to how pervasive ideologies of toxic masculinity remain, survivors who are men may have to go to greater lengths to assert the legitimacy of their experiences even in feminist, prosurvivor spaces. I digress briefly to examine the specifics of how rape culture and patriarchy influence the experiences of survivors who are men. Later in our conversation David commented that,

You've got to remember, and I would address this during the performance, you've got to understand, I'm a male survivor. Up until recently it was thought that men couldn't even get raped. So if a man does get raped, in our society a man isn't left with too many options on how to deal with it, right? There's substance abuse, violence, humour. So, humour is the most socially acceptable of the three, but it's still not that acceptable to joke about stuff like that. So when you're hearing my jokes, you've got to understand, that's my perspective.

Without explicitly naming either rape culture or patriarchy David clearly articulates how they impact his life. Systemic patriarchy relies on sharply defined gender codes for its continued dominance. Pushed to extremes a toxic form of masculinity develops wherein men are required to be stoic and aggressive at the expense of expressing any emotional vulnerability. One implication of this is that masculinity is defined as incongruent with sexual victimization. The gender of a man's abuser often determines the cultural response to his disclosure. Men who come forward as survivors of sexual violence perpetrated by women often face scepticism as to the validity of their claims. An exception to this situation can be found in the vilification of adult women who abuse teenage boys, as has played out in media coverage of teachers revealed to be assaulting their students. Even when these survivors are believed, however, claims are still often made that the boys in question were lucky in some way to have had sexual experiences with an 
adult woman. In this vein toxic masculinity promotes an understanding of men and boys as constantly desiring sex, so when they say that they have been forced into sex that they did not want they are pushed towards the margins of their gender. Furthermore, the emphasis toxic masculinity places on male aggression can undermine male survivors' claims of violence. While survivors of all genders are often hit with the argument that if they were truly opposed to sexual interaction with their aggressor then they would have physically fought them off, survivors who are men have the very legitimacy of their gender called into question with this line of reasoning. Discourses of homophobia play heavily into cultural responses to violence inflicted by men onto other men (Butler, "Critically" 27). Although these disclosures may garner more empathy from other men than situations in which women were perpetrators of violence, that affective response is grounded in the homophobic disgust of gay men. Patriarchy and homophobia are intertwined through heteronormativity in understanding homosexuality to be a refusal of certain fundamentals of masculinity, namely the cultural and sexual domination of women. In his set Mayer confronts the cultural response he received when he promoted his participation in a standup show about sexual violence:

And then when I decided to be in the show it was interesting "cause I started telling friends and family that I was going to be doing this show and when I talked to them and I said, "I'm going to be involved in a thing where you get up on stage and it's for comedians who have experienced rape," I know some of them were looking at me like they wanted to ask, "Which side did you experience it on?" Yeah, I'm up here presenting the piece of shit rapist point of view, that's what I'm doing.

This bit illustrates toxic masculinity at work: assumptions of male aggression and constant sexual desire feed into rape culture's project of discrediting all survivors of violence. 
Further research is necessary in order to explore how gender dynamics inform the experiences of comics who perform material about sexual trauma.

While a singular performance may leave a comic with a glowing feeling, such as the Christmas morning feeling Simone referenced above, trauma theorists insist that the real work of transforming traumatic memories happens with the repetition of those narratives. Cvetkovich compares this process to that of coming out as lesbian, bisexual, gay, or transgender, and argues that breaking one's silence about trauma has to be "understood as an ongoing process and performance, not as a punctual event" (94). Similarly to Brison's early accounts of being unable to control where, when, and for how long she thought about the vicious attack to which she had been subjected (Brison, "Everyday" 190), Victoria mentioned that,

I think about my sexual assault every single day. Every single day it comes up once. I'm just like, "Okay, there it is." Every day it's like, "Did that really happen to you? Are you not just, like, making a fuss?" It's absurd.

The outward repetition of traumatic memories can work to supplant these internal recitations as the survivor gains control over the narrative. Arguing that repetition is at the very heart of working through trauma, Butler writes that, "There is no possibility of not repeating. The only question that remains is: How will that repetition occur, at what site... and with what pain and promise?" (Excitable 102). Stand-up comedy is one site that, designed to generate positive affect and to facilitate the repetition of material over the course of several shows and sets, survivors can use to recruit supportive publics to bear witness as they work to transform their relationship to trauma. Nancy described how the process of writing material, repeating it over the course of several shows, and having conversations with audience members after her performances changed how she framed an assault that she had experienced: 
I tried to talk about it calmly to force myself to look at it and pick it apart and work on it and get reactions to see what people thought. So the first time I talked about it I ended it up by saying I was someone who chose to get drunk, stoned, to have sex with a stranger, this happened, and I need to own that, was basically my takeaway... And I didn't really think about that as a rape, I just thought about that as an interesting grey consent story, and I'm sure so many of us have these interesting grey consent stories, so I should talk about it. By the time I talked about it a few times and got feedback, there were other women who were like, "No, if you never said yes to that then that's sexual assault, that's what it is." So it was while doing this tour that I actually figured out how to label that experience and kind of how to reconcile it.

Although most participants expressed having had positive experiences with their performances and offered details to support the claim that elements of stand-up comedy lend themselves to helping people work through trauma, these reactions are not guaranteed. The most significant risk expressed by participants was that the audience would not react in a desirable way. Although this is a common concern for all comics, a negative reaction from an audience or audience member can be particularly damaging for comics who are using their time on stage as part of a therapeutic process. In these cases something more is required from audiences than simple voyeurism in order for a survivor-comic to make progress of their own (Cvetkovich 93). The following four quotes from David, Katie, Nancy, and Avery offer insight to how critical an audience's role is in supporting survivors on stage:

Some people say doing comedy is therapeutic, eh, sort of. It's not therapeutic in the way that, “Oh, because I talked about it in public now I'm de-stigmatized and I've removed all the shame from it," I wouldn't say that. I can talk about my own experience with sexual 
violence and people could still get fucked off at it. Then it turns into a negative feedback loop, because it's like, "I knew I shouldn't have talked about that, look what happened." You're dealing with, let's just use a round number, let's just say you're performing for a hundred people. That's a hundred different personalities. You don't know how anyone's going to react to that. In order for it to be therapeutic for me I can't be reliant on a hundred different people to help me process it.

It was just a really cold room. Everybody was just kind of sitting there looking at you and judging you. Maybe I was projecting a bit there because I'd lived there for a time and I knew people in the audience, so I was like, "Hey! This is the thing that happened to me here! And I'm going to leave, forever! Good luck staying here!' I felt weird. The energy wasn't great. It was a weird room and everyone just took off afterwards.

I would have people come up to me afterwards and tell me, "No, no, that can't be rape, that story's not rape." It's this interesting thing where you get feedback from people with whom you're not trusted friends on something like that... [Mainstream] comedy is not really an ideal place to talk about stuff like that if you're looking for someone to be a little more supportive because it's just a mixed bag of people and you've got five minutes. People are not expecting to hear a story like that, so it was a bit of a weird thing. There's a bar that's typically straight cis male white dudes doing jokes about their family or ding-dongs, and then I came in with a story about being molested. It totally bombed. It was really bad. I felt really bad. I also make myself very vulnerable, and then to have someone shoot that down really... It was triggering, but triggering was okay. I felt stupid, I felt really dumb because it made me feel like maybe I should not be so vocal about it... I think it might be interesting to try and tackle it in a more safe environment. Where I do 
[comedy] now we've had a few people come out, not with sexual trauma but with other forms of mental illness trauma and stuff, and I do find that it goes over a lot better in certain spaces.

A central consideration for all survivors interested in performing comedy or producing stand-up shows about sexual trauma should be on bringing out an audience ready and willing to support a diversity of voices on stage.

Infelicitous

Speech act theory is one lens through which we can consider how successful a survivorcomic's performance might be. Brison writes that "the same utterance could be (at least) two kinds of speech act: one of bearing witness (describing events as they occurred) and one of narrating or working through (and thus transforming) traumatic memories" (Aftermath 72). A comedy performance adds a third type of speech act to the mix: the telling of a joke. Any combination of these three acts may succeed or fail independent of the other(s) at any time. Comics who can successfully wrangle their memories into a cohesive narrative punctuated by humorous insights or startling connections, and who are then able to recount that narrative, from memory, to an audience likely composed of strangers, are accomplishing a remarkable task. I do not want to underwrite the labour, both cognitive and emotional, invested in such a project, and I would like even less to give the impression that this is a risk-free endeavor. On the contrary, David, Avery, Nancy, and Katie each underscored the difficulty of crafting a set that resulted in felicitous conditions for all three attempted speech acts:

Just 'cause they're a survivor and they're talking about being raped or molested when they were a kid, eh, there's still the artistic and craft part of it - the jokes weren't always 
funny. Sometimes it felt like, 'Uh, you know what, you need to really sit down and process that stuff a bit more before I think you can present it to an audience.

I'm a victim of sexual trauma. I have a solid two to three minutes about it. There's a lot of one-liners. They definitely vary. It's actually really interesting, because I find that you can't be too direct. I've tried in the past to just do a storytelling format of it, where you just recall the events and people get really uncomfortable from it and not necessarily from a sympathetic point of view, more so I think they're trying to have a good time and it kind of bums them out, essentially.

I've really had to learn the hard way that if you're always driving towards an agenda then you lose people because you're no longer doing stand-up comedy, you're just a person on a soapbox. Comedy's a good balance to pull you back.

Some peoples' stories... I really felt like maybe there should have been a little bit more talking about it beforehand because some people went up and it was just like, oof. There's no punch-line here, it's just... and I'm glad that you're going through this and you're sharing this and it's important, but for me personally I'm a big softie and it got to the point where I couldn't watch the rest of the show because I couldn't cry before going on stage.

What compels survivors of sexual violence to pursue stand-up comedy as a platform for working through trauma is a topic for another study. What I've attempted to lay out here is an analytical engagement connecting theories of trauma, of culture, and of communications with impressions offered to me by comedic practitioners about the work that they have done. My argument, that stand-up comedy offers a particular structure and conventions that can assist and at times even guide survivors of sexual violence towards integrating their trauma with their 
present and future selves, is based from the successes my participants have so gracefully shared with me. I end this section with words from Victoria:

People ask how we can joke about this, well, because I'm a living, breathing human being. I've got to live with this every day. You can read an article and then walk away but every day I think, "Gee I got raped two years ago." If I'm thinking about it I might as well crack some jokes about it. And I want to be talking about this. I want to get it out of my system and I feel good about it because I love making people laugh so I'm dealing with my issues and I'm making people laugh, and that's the dream. 
CHAPTER 5: Survivors in the mainstream

Absence of social scripts for responding to violence

A symptom of rape culture's discursive domination is the absence of social scripts to rely on when responding to accounts of sexual violence. Bringing up the topic can plunge unprepared listeners into paralyzing awkwardness and result in situations where the survivor feels alienated when the respondent blurts out an unsatisfactory or harmful reply (Brison, "Surviving" 13). These interactions can reify trauma for a survivor whose position in the world has already been rendered precarious by the initial instance(s) of violence (Jackson 222). Those of us asked to respond to disclosures of trauma have the responsibility to recognize the power we have in those moments to respond in ways that can contribute to the restoration of the survivor's sense of self and security (Jackson 222). But how do we learn what constitutes a truly helpful, compassionate response when we have such strong aversions to speaking openly about sex, violence, and power? The following sections of this chapter will analyse how humour can function as an educational tool to prompt audiences of non-survivors to rethink their understanding of rape culture and the complexity of its implications. Comedy produced and performed by survivors of sexual violence can be particularly compelling for these purposes since personal writing is one way of skirting cultural barriers and introducing an unfamiliar other to one's own perspectives, history, and humanity (Hodges Hamilton 197). The jokes referenced in the following sections will demonstrate how humour has been used to reduce defensiveness from listeners as well as to build atmospheres of provisional safety in which critical thinking and reflection has taken place. An analysis of these works demonstrates how the element of surprise inherent to many expressions of humour can be mobilized to promote new avenues of thinking, and how ridicule can be employed to impress preferred modes of thought and conduct on willing listeners. This chapter concludes with an overview of the potential social risks associated with circulating 
discourses of sexual violence and offers an alternate perspective on the major tenets of that debate. Although this and the following chapter are structured along strictly divided lines of audience members' survivor status it is of course always most likely that any given audience will include both survivors and non-survivors. The distinction between these groups is being made here to conduct more specific investigations into how performers engage in comedy about sexual violence based on their perceptions of different audiences.

Humour as educational tool

Some rape prevention programs have written light humour into their content. Making a few jokes during the early parts of what can be an emotionally taxing presentation or workshop can help participants relax and perceive the facilitator(s) as likeable and non-threatening (Meyer 312). Prevention programs are frequently run in environments where the prevalence of sexual violence is highest, most notably on post-secondary school campuses. A barrier to educating college-age men about sexual violence is the possibility that they will react defensively when the topic is broached (Rich et al. 270). Although not all sexual violence is perpetrated by men, statistics show that most is, including most acts of violence in which men and boys are also the targets (Maxwell; Perreault; Foubert et al. 2238). These trends require an urgent critical investigation into how our culture constructs and validates dangerous expressions of masculinity, especially on the part of men who have already begun to conform to these expressions. The interACT project, founded by Marc Rich, uses a performance activism and social justice perspective to generate critical thought and empathy for women and assault survivors in college students. He explains his decision to integrate humour into his productions by writing that the “opening scene is a strategic way to get college males to laugh at themselves, and we are able to introduce the topic of sexual assault without triggering a defensive response" (Rich 515). The 
opening scene he references is one where young men banter amongst themselves onstage in a subtle parody of toxic masculinity. The representation is realistic enough to appear familiar to audience members and is performed by men from their peer group, elements that Rich argues are essential to helping an audience feel comfortable and, therefore, ready to learn (514). Some theorists who study prevention programs suggest that men learn best about sexual violence from other men (Foubert et al. 2240). Rich disputes this and argues that such a position is disrespectful to men, as it implies that men are somehow inherently lacking in facilities that allow them to empathize with and relate to people unlike them (520). Additionally, he is unconvinced that depicting only male-on-male violence encourages any critical reflection of audience members' own participation in patriarchal, misogynist rape culture and violence against women (520). My own research supports the idea that men can learn anti-violence ideologies from people of other genders. This is demonstrated from the reactions one of my participants, Lisa, has overheard from men in audiences at her mainstream shows:

I'm surprised at how much men laugh at me, because I'm shitting on them so hard on stage sometimes and they're just like, [laughing wildly]. So I have heard, and it was like, “Oh! Yes!'” I have heard sometimes guys say, “Oh shit it's true, I never thought of it like that!” Which is like, "Yes, score!” And when it's like this douchebag frat boy kinda looking guy I’m like, “Extra point.” It's very satisfying.

The men in this example were understood to have learned something about social and gender relations despite that information coming from a woman. This is of course anecdotal evidence provided by one participant, and, with an eye to gender dynamics, it is very likely that there are men in our culture who take more kindly to instruction by other men than by women or gender-diverse people, but it also points towards the benefits of supporting a multiplicity of 
educational fronts. Rich writes that, "As the media and popular culture continue to perpetuate messages that objectify women and blame them for their own victimization, programs that can induce empathy for rape survivors are needed" (Rich 518). Humour is often used in social settings to engender goodwill between people by rhetorically reducing their dissimilarities, one strategy towards the development of empathetic relationships. A different participant, Simone, spoke to me about the speaking engagements she does in local schools, an opportunity that arose for her after she came out publicly as a survivor of rape.

I like that there are always boys in the audience. For so long this was "a women's issue," and these shows or communities are just girls and it's passed off as a feminist thing that guys don't have to worry about. But I think it's really important for guys to hear these stories. I think consent, you can mock people for not understanding the difference between yes and no but it is really a grey concept that a lot of people don't understand. I don't think we should shame people for not understanding it, we should help them understand it. If making jokes about it helps, if showing weird videos on YouTube helps, if telling sad stories helps, whatever it takes as long as... even if it prevents one guy from doing something, it's worth it.

She encourages a diversity of prevention methods in line with Rich's findings on the importance of empathy. This participant differentiates between two ways humour can be used as a tool of education. She refers to humour as a method of increasing men's comfort and interest in learning about sexual violence prevention when she lists "making jokes about it" as a potentially successful tactic - this is in line with how humour has been theorized above. This participant promotes an inclusive use of humour but she also acknowledges that humour can be used as a disciplinary force. She refers to mocking and shaming people who don't understand consent and 
argues that these approaches have little or no educational benefit. While ridicule typically does little to engender feelings of empathy or inclusion in its targets it can work to clarify social conventions for all involved. Deviating from expectations set by a social group, large or small, can prompt others in the group into discipline by laughter, revealing the norm for those who were previously unfamiliar, and reinforcing the cost of deviation for all others (Meyer 320). Humour can be used in a variety of instances, scripted or impromptu, to direct people towards certain ways of living.

Reconfiguring social norms

Part of the impact of rape culture's dominance has been a reduction in the types of interactions understood to "count" as sexual violence. Fahs attributes this to its sheer pervasiveness: "men internalize the perpetration of such violence as normal and women internalize sexual violence done to them as normal" (63; emphasis in original). The rare cases that are taken seriously by dominant players and systems are portrayed as aberrations to the norm, thereby subsuming the violence many of us endure in our daily lives as, in fact, normal (Fahs 63). Sexual coercion through guilt-tripping or drug and alcohol use and the sexual harassment or stalking of acquaintances or work-mates are examples of sexually violent behaviours that have been reclassified as normal for men to perpetrate and for women to anticipate and manage. In this way the banalization of sexual violence serves its propagation. Simone voiced her frustrations with how readily the police have adopted this perspective:

I always say, "If you don't want to go to the cops, don't go to the cops." For me they're completely useless human beings with no training in this area, so until that is fixed, until they know how to adequately handle this, don't do it... Unless you can check off all these things where you caught it on camera, you have a text from him saying, "Yes I raped you," 
you went to the cops immediately, you went to the hospital and did a rape kit, unless you did all of those things, don't even bother. And you better not have been drinking that night! In this quote Simone explains her perspective on how the police normalize and dismiss the vast majority of sexual violence people experience by relying on rape culture's dominant discourses as accurate information despite their wild divergence from data released from other sources (Perreault). These attitudes foster a culture of violent policing that has resulted in extreme rates of sexual violence perpetrated by police officers themselves, especially against racialised and Indigenous people. Since comedy feeds off of revealing incongruities, comparing disparate perspectives, and questioning the frequent absurdity of social norms, rape culture becomes a ripe target for humour. A mainstream stand-up comedy show can then become one location where rape culture is critiqued and people are encouraged to think differently about sexual violence. Victoria described one joke she tells regularly for audiences at mainstream events in this way:

I always had my anti-rape jokes, so I had these jokes that I always told, which were kind of sneaky little punches at the regular style of rape jokes. I had jokes where I said, "I find it really interesting that guys really defend their right to tell rape jokes, and there's a line that goes, 'if you can tell a murder joke, you can tell a rape joke.' But I don't know if one in three men in this audience have been murdered, so I feel like we're talking about something a little different here."

She uses her time on stage to introduce a familiar idea (the debate over who can and cannot tell a rape joke), repeats a commonly accepted comparison (murder and rape as comparatively horrifying acts), and then points out the flaw in that reasoning (people, specifically women, are raped at a higher rate than they are murdered; no one in the room will 
have memories of their murder being triggered by a glib comment a non-murdered person is likely to make). The humour here relies on differences: the different positions people take in debates about rape jokes and the different implications joking about rape and joking about murder might have on audience members. The very tensions thrumming at the heart of these differences make a successful joke possible. This indicates the potential of humour as an educational tool: "Though humor relies on differences, it nonetheless creates a momentary pause, a surprising fraction of time in which the antagonisms that precede the moment of concord abate ever so slightly in order to allow what one might think of as contingent communication" (Mayo 511). That fraction of time provokes a listener to momentarily hold both perspectives in mind in order to recognize the tensions that make the conditions of the joke possible. Another example of dual perspectives introduced by a joke can be found at the end of Mayer's set. After offering his opinion about how the word 'molestation' diminishes the severity of childhood rape, he quips:

I also don't think that we should use the word rape anymore to be honest, I think we should change that word to something that the courts will take a lot more serious. So I think from now on we should call all rapes "tax evasion."

This joke can provoke listeners into reflecting on the disparity between how seriously certain crimes are taken by our justice system. Not only are the courts not equipped to deal with the ubiquitous and insidious realities of sexual violence, but court processes are often retraumatizing for survivors to experience and rarely award us legal justice (Herman 72). Mayer gestures with levity at this deeply inequitable system in an effort to provoke a momentary pause in resistance from listeners unconvinced of rape culture's reach.

Since mainstream comedy shows draw audiences from the general public (and are typically white, cisgender male-dominated spaces) it is likely that the people forming the group 
entertain a diversity of political opinions. Jokes like the ones quoted above carry the risk of dividing an audience into factions based on the differences and tensions they elucidate and emphasize. Meyer suggests that divisive humour functions by emphasizing the violation to the norm rather than the security of the norm itself (325). Reading Meyer in this context requires a rethinking of his use of "social norm." Since, as I've argued, perpetrating, excusing, and anticipating sexual violence have become normalized behaviours in our rape culture-dominated environment, we experience a bizarre contradiction of values when we describe our social norms, which are otherwise guided by politeness, generosity, and respect for others ${ }^{1}$. Rather than fixing “social norm” as a descriptor of macro-level values, I instead interpret Meyer's theories to be flexible and applicable to smaller group-level discourses and emerging structures of feeling. Victoria, quoted above, is speaking from a perspective that considers any act of sexual violence to be a gross breach of feminist social norms. In her joke she underscores the frequency by which women are raped and insists that though debates about political correctness within the comedy scene can be laughable, they are "an unacceptable violation that [need] to be focused on, corrected, or avoided in the future" (Meyer 325). Listeners have the agency to focus on either perspective offered by the joke; audience members willing to entertain feminist thinking may appreciate the emphasis on anti-violence, while people who are more resistant to feminism may be affronted by the suggestion they quit telling rape jokes. Laughter in response to this joke might then communicate any combination of pleasure, recognition, surprise, or incredulity. Despite the range of responses that humour has the potential to elicit, it remains that listeners have had to hold at least two contradictions in mind and do the cognitive labour of sorting and interpreting those tensions in order to generate a response at all: this is the hinge on which

\footnotetext{
${ }^{1}$ Similar reversals can be witnessed with regards to racism, classism, xenophobia, and other systems of oppression.
} 
comedy's potential for education hangs. Another example of a joke that demands that its listeners reconcile disparate ideas is the following:

I chose to focus a little bit more on the systemic rape culture and how people are treated after you come out as a survivor. One of my jokes, for example, was about how people get really upset when they come out as sexual assault survivors, especially when you're accusing someone who's a high-profile person, like an athlete or whoever, and you're accused of being a gold-digger or you're in it for the money. But at the end of the day I don’t know any women who've hit paydirt just because they’ve accused someone of raping them, you don't log on to LinkedIn and somebody says "Rape survivor," like that's what they've been doing for the last five years. That's not a thing.

Here Simone draws on the myth propagated by rape culture that women accuse wealthy men of sexual violence in order to win large sums of money as settlements. She places this misogynist assumption in tension with the absurdity of witnessing someone claim "rape survivor" as their main source of income, and emphasized the implausibility of that scenario. This joke clarifies the incongruity inherent in the claim that women "cry rape" for financial gain. Humour can encourage people to reread the "concept played with by the joke or wordplay in a way that opens new ways of thinking about the concept and thinking about the group of people involved in the joke" (Mayo 512). In other words, comedy can be a low-pressure setting where audiences can be prompted to practice critical thinking about gender relations and sexual violence. Impressing a preferred framing

Not only can humour function as a method of introducing alternate perspectives but a proficient speaker can also use it to impress preferred framings upon people. Any social group 
can use laughter to instruct people about their boundaries of acceptable social living. Two perspectives emerge here. First, Meyer theorizes this type of laughter as demonstrating feelings of superiority over others (314). He argues that the negative impact the target of this laughter will experience will shame them into conforming with what the larger group desires, thereby effectively enforcing any given social norm (317). This theory emphasizes humour's ability to communicate hostility. In contrast, Mayo prefers a framing of generosity rather than aggression when writing about humour being used to administer social norms (514). He cites French philosopher Henri Bergson at length and suggests that rather than driving towards individual glory, those who laugh at others' social missteps are intending to "push the ridiculed person into a realization that they have not kept up with the social group's capacity for critical thought and adaptive change" (514). They claim that this ridiculed person has become "inelastic" and is in need of "reinvigoration" - a duty the surrounding social group has a responsibility to perform (514). Lisa, who performs comedy about sexual violence at mainstream shows where she lives, framed the way she thinks about performing to men similarly to Bergson's and Mayo's perspectives:

I also want to do it as a public service announcement for men, so a lot of times it does actually shape how I'm writing my jokes. I'm writing it in a way that will get the point across and that won't scare off men. Like, I'm hiding my feminist message.

The impact of hearing these jokes may extend past momentary surprise or amusement and influence listeners' lives after they disperse from the group and leave the club. This material can also be instructive for non-survivor audience members who are comics themselves and who are interested in writing their own material about sexual violence. No participant I spoke with implied that survivors of sexual violence somehow owned or were the only people who should 
be performing rape jokes. Again, two perspectives emerged here. As comics, participants were disparaging of performers who relied on lazy punch lines or unimaginative topics, like rape survivors and rape, to garner easy laughs. Making reference to hearing tired rape jokes trotted out by performers at open mic nights, one participant, Katie, said:

Open mics, it's where you go to suck. That's what you're there to do. Usually if someone says something bad, that's only ever happened a couple times where I've walked out of the room or talked to the person afterwards, being like, "Can you do this in a way that's funny?"

Simone complained about the apparent lack of effort many comics seemed to put into their jokes about rape:

I wouldn't say, “Ha, ha, ha, rape is hilarious, that's so funny, you got raped.” There's nothing funny about that. I always just hated rape jokes because they always seemed lazy. It was always these white male dudes making rape jokes because someone told them they couldn't, and that was the one thing you can't do, and they're trying to piss people off and so something edgy. Maybe you should actually write a joke that's funny! Your joke is not funny. Not the content, the topic, it's just that your joke is not funny, that's why I'm not laughing. But I think if you're smart about it and write a joke that's actually funny, people will laugh.

A comic who performs this type of material about sexual violence may see themselves as breaching stuffy, over-sensitive codes of behaviour in rebellious and emancipatory ways (Billig 211). This may feel like a politic of liberation for the performer in question but critical listeners will hear the repetition of dull, conformist values in their set. In the following joke Mayer uses this common misunderstanding of rebellious humour to poke fun at his younger self: 
A lot of comics, when they start out, they do start out by doing rape jokes. Just shock-value humour, which is terrible. And they want to do it because they think it's edgy, right? I'm gonna be honest: when I first started doing comedy, that's the kind of thing that I did. I remember being at [a] comedy club, getting up on stage for a competition, and I opened with a rape joke. Very low-brow humour. And a lot of people laughed, but there was a table to the right of me that clearly were not having it, they were offended, this group of ladies. And in the moment I thought, "Ha-ha, I'm so hardcore, I'm so edgy, look at me," and I said, "Wow, I lost this whole table already, you're going to love the next joke, then." And I went and told another rape joke. And on the way home that night I was thinking about it, and I started wondering, well, why were they so offended by that? I started questioning it in my own mind. And I realised really quickly, well shit, obviously one of them has been raped in her lifetime, maybe even more than one of them. And here I am on stage revictimizing them. And I felt like a total piece of shit for doing that. And I decided in that moment that I was never going to do that again. Nope, I've had enough, not going to do it. And yet here I am, doing a full set on rape jokes. Ten minutes of rape jokes, going against saying that I would not do it again. So I guess maybe, sometimes, no doesn't mean no?

Mayer's self-reflection gives us a glimpse into the trajectory of his growth as a comic. His joke is also an example of how feminist rhetoric can serve as a punch line without generating bad feeling towards feminists themselves.

Crafting genuinely funny and innovative jokes was the top priority across all of the comics I spoke with. The other perspective that was repeated by several participants was that, whether a performer was a survivor of sexual violence or not, they had a social responsibility to engineer 
their material in ways that supported survivors and condemned rapists and rape culture. Victoria said this:

[My comic friend] and I have always said we're not the only ones that get to or can tell rape jokes. Just think about who you're supporting. When that comedy show wrapped up and everybody goes home, who feels comfortable? The rapist or the survivor? And whose side do you want to be on? Some people don't get that because rape is this obscure concept to them.

Another participant, Avery, referring to women in his comedy scene who do not publicly identify as survivors of sexual violence, had this to say:

I hear some [rape jokes] from some female comics who use it in a way that is not making fun of rape. They made Jian Ghomeshi jokes, so it's not necessarily coming from a catharsis place, I think it's more just like overall from a feminist perspective. Which I think is cool.

On the other hand, David disagreed with making a link between discourse and culture. He argued that:

Have you ever heard this concept in comedy of punching up and punching down? People say never punch down, always punch up. I've heard tons of funny jokes where the fucking victim was the butt of the joke. It can be done. It's all about how you do it. There really is no rule when it comes to comedy other than make it funny... Some people say comedians have a social responsibility, ehh. I don't know. That's giving us a lot of power. I make dick jokes and stuff, come on. Give me a break. I have social responsibility off-stage. Let's use Cosby as a perfect fucking example. It's my off-stage conduct that dictates what my character's like, not what I say on stage. On stage is a performance. Like a play, like a 
movie, like a song. Cosby was one of the cleanest comedians in the world, he used to tell comedians not to swear. And then he'd go rape women.

This participant distinguishes between the "performance" of comedy and the off-stage conduct that accompanies it, using accused serial rapist and former celebrity comedian Bill Cosby to illustrate the disparity between speech and action. Considered from a critical gender lens, the quote from this participant suggests that although he has been subject to sexual violence and lives with the trauma it imposes, his perspectives are still influenced by his privileged gender position. Women participants of this research project were more likely to make connections between language and action and to point out the embedded relationship between mainstream anti-survivor discourses and the enduring prevalence of sexual violence in our culture. Nancy spoke about these connections directly:

[Open mic events are] sort of a site in comedy where people are like, "I should be able to have free speech and say what I want," but the totality of going into an open mic situation is there's just enough new people who are often young guys who will show up, and they're responding - comedy is a by-product of our society, right, so they're taking any entitlement or recycling humour that they've seen in other places and filtering it through their experiences, and what they're coughing up, oftentimes, are rape jokes that punch down at the victim. You only need to hear one or two of those to have an uncomfortable feeling because if you're sitting in a room and you don't know people very well and everyone laughs at the joke and you have any concept or a personal experience with sexual assault, it pretty quickly gets to be really uncomfortable. Especially with someone in your own community who sexually assaults you, you can see that it really divides your friends and all of a sudden you don't just have to deal with this trauma, you've got to deal with 
losing out on all these people in your life. Even just laughing at a rape joke, it can look like the most harmless thing from one perspective and it can look like an incredibly threatening thing from another perspective. I see both sides, but that's why you need to really be able to defend your work and understand what you're trying to accomplish from the rape joke.

Rape jokes like the one Nancy references operate alongside Meyer's theory of superiority: mirth is first felt due to feelings of superiority the joke inspires, and then those feelings of superiority are communicated through laughter (Meyer 314). Nancy describes such situations as potentially "incredibly threatening" for survivors to witness, while Meyer writes that being subjected to this type of laughter can induce "disagreeable feelings of threat to our identity" as we are interpellated once again into a victimized subjectivity (Meyer 314). A critical theoretical approach to humour, laughter, and culture clarifies the ways in which dominant groups are already using humour to maintain their power status over more marginalized social groups and lends a supportive framework for survivors doing the subversive work of deflating the logics and egos of their oppressors by laughing at them.

Potential cultural risks

According to some theoretical perspectives, even rape jokes that conform to the two criteria most participants agreed upon - that they be thoughtful, imaginative, clever pieces of writing, and that they communicate ideologies of resistance and liberation for survivors of sexual violence - can carry social risk. Brison writes that while women's narratives of surviving sexual violence can be transformative both to produce and to consume, there is a danger involved with privileging these discourses over other stories women tell (Aftermath 95). She warns that the popularization of these narratives runs the risk of "perpetuating one's self definition as victim and others' stereotypes of one's group as weak and helpless" (Aftermath 95). Projansky's 
concern about representing rape in film runs along a similar line. She, like Alcoff and Gray, warn that even well-meaning, but uncritical, representations of violence and survival can become subsumed into dominant systems of meaning (Projansky 230; Alcoff and Gray 270). Survivors' stories are frequently co-opted into mainstream media discourses that flatten the subversive potential of their speech by feeding it through "expert" (non-survivor, medical) mediators who interpret and validate the survivor's experience for a wide audience (Alcoff and Gray 277). Survivors and allies must come to recognize these discourses as strategies by the dominant classes to recuperate our speech. Projansky insists that a truly radical anti-rape discourse must "struggle not only against rape, but also against the pervasive and persuasive power of the cultural narratives about rape and the cultural imperatives to represent it in particular ways" (230). I intervene here to interrupt Brison's assumption that survivors' narratives necessarily take mournful, emotionally heavy tones. Survivors' comedy and laughter bust open these affective stereotypes and work to transform rapists and rape culture into objects of ridicule. Survivors who take to the stage by themselves shrug off the hovering imposition of expert interpreters and assert authority and autonomy over their own voices and experiences. 


\section{CHAPTER 6: Between us}

Humour and the formation of social groups

Humour about sexual violence can serve very different purposes when performed for an audience of fellow survivors rather than for mainstream audiences. This chapter investigates how survivors are using humour to reconstitute supportive social networks, how staking a claim to the physical space of the comedy club can be part of a therapeutic process, and what impacts witnessing other survivors joking about sexual trauma can have on someone who lives with trauma of their own.

A common outcome of surviving sexual trauma is the sudden or gradual loss of the bulk of a survivor's network of friends and sometimes family. This can result either from social pressure to pick sides after a survivor discloses the violence and names their abuser(s), from the emergence of trauma symptoms into the survivor's life that changes their ability or desire to socialize, or, perhaps most frequently, from a combination of the two. Stand-up comedy creates a space where audience members can enjoy a social environment without the pressures of necessarily engaging directly with other people - any individual can enter a club alone, watch a performance as part of a group, and then leave. Even this transient experience of group membership can be transformative for survivors.

Laughter and humour are generally understood to be social actions that generate joy, relief, and pleasure (Meyer 311; Billig 28). What many survivors and otherwise marginalized people are all too familiar with, though, is that those positive emotions are typically reserved for those who are either making or in on the joke, with people who are the butts of the joke left feeling distinctly otherwise. I wrote earlier on the propensity of actors involved with rape culture to use humour to mock those of us who have survived various types of sexual violence, or who live with the expectation to do so, and I frankly don't find those perspectives worth revisiting 
here. What I turn to now are the ways in which some survivor-comics are harnessing the groupformation qualities of humour to design spaces and generate feelings of unity and support between themselves and audiences of other survivors. Part of the appeal of humour is its flexibility in this regard: in and of itself it has no ideological undercurrent. Humour can be used to encourage "the laughter of hostile ridicule or the laughter of friendly appreciation: one can laugh with others and at others. As such, laughter can join people together and it can divide; and it can do both simultaneously when a group laughs together at others" (Billig 194). Our social codes currently teach against laughing at others - from childhood we are warned that it is cruel and impolite to make pleasure out of another's flaws or foibles. While certainly true in most cases, I seek to trouble this blanket statement by inquiring about how stratifications of power function to censor particular laughter. Meyer writes that, "Human society is kept in order as those who disobey are censured by laughter, and people are made to feel part of a group by laughing at some ridiculed others" (315). Considering that rape culture is currently an integral element that guides how our human society is "kept in order," as he writes, then what he refers to as "those who disobey" are, in fact, those who speak out against sexual violence, not those who perpetrate it. The aim of rebellious humour, as Billig terms it, is to overturn the social codes that keep this structure of violence in order (202). In this case good feeling would be generated by and shared between survivors of violence as they ridiculed and mocked the social systems that upheld the power their aggressors enjoyed. Phenomenological analysis has led to these types of jokes being labelled as liberation humour, a designation that helpfully emphasizes both the existing conditions of domination as well as the potential to be liberated from them (Billig 39; Du Pré). Nancy articulated her goals in producing comedy in the following way: 
I guess comedy's an extension of how I would like to listen to people, because at the end of the day I want to remind people that while we're all taking responsibility to an extent for ourselves as people, it's not your fault if something bad happens to you. You deserve support, you deserve love, you don't deserve to have your life destroyed. Just real basic things. I would try to tell someone that. I try to find ways to package that into the comedy on some level so that people hopefully feel that by the time they leave.

Liberation humour can also be understood as involving elements of relief. A relief perspective on humour suggests that "people experience humor and laugh because they sense stress has been reduced in a certain way" (Meyer 312). For survivors, simply being welcomed into a space that acknowledges our trauma and prioritizes our comfort can be a huge relief. A survivor-centric comedy show can create a temporary social pocket where sexual violence is worthy of mockery and where survivors at different stages of living with trauma have the opportunity to practice re-integrating themselves into safe, trustworthy communities. Value of connecting with other survivors

If we shift our focus towards the survivors who choose to bear witness as audience members at comedy shows about sexual violence we can explore what impacts hearing liberatory jokes about trauma might have on these people. It can be very useful for people who have been marginalized to learn about the systemic nature and socio-historical context of the oppressions they have lived (Disch 221). This can help people frame their experiences not as individual acts of violence but as collective histories that countless others have struggled with and against (Disch 221). Comedy about sexual violence can serve this educational purpose. I wrote earlier about how the process of repeating one's narrative and speaking with audience members about it can shift a survivor's perspective about events they have lived through. Being an active listener 
to this process can help survivors in the audience reorganize their own definitions and assumptions when it comes to their life histories as well. Nancy described how audience members would speak with her after her set to tell her how her story had encouraged them to name their own experiences as rape for the first time:

Once I've talked about sexual assault I've had people come up to me afterwards and have those private conversations where they say, "Your particular situation with the condom is exactly what happened to me," so I did get on the tour a lot of people who came to say, "Yeah, I just had this grey thing and I didn't know that I could call it [rape], so thanks for saying that, because I never would have known.” And then you're like, “Oh, okay, this is a thing that happens to a lot of people, I can go forward and say that joke with more confidence, in a way." So you're almost seeing the gears of understanding and learning turning through those conversations.

Some research on trauma suggests that, "the rebuilding of the self after catastrophic events is relational and requires the support of others through mirroring experiences" (Schwab 120). The successes of support groups and group therapies can be attributed to this perspective as well. Just as the participant above detailed how her description of rape sparked recognition and transformation in some audience members who spoke with her post-show, the following quote from Simone, who has a relatively high social media profile, demonstrates how she engages in mirroring relationships with strangers who contact her:

I think sexual assault is really isolating. Just being in the position that I'm in a lot of people reach out to me who are survivors. Sometimes I don't feel equipped to deal with that. People will be like, "It just happened to me two weeks ago and I don't know what to do, can we meet for coffee?” And I will, and I'm pointing them towards the right resources, 
but I'm not a counselor, I'm not qualified, but sometimes just having somebody who knows what you went through and is willing to listen and just talk about your shared experiences, you end up making jokes. I met a woman for coffee not long ago who had recently been sexually assaulted and you end up making jokes to each other. They're dark and weird and no one else would find them funny except you two, but it's necessary otherwise you would be miserable all the time.

Survivors connecting with survivors on our own terms is part of the feminist process of social change. bell hooks writes that, "storytelling becomes a process of historization. It does not remove women from history but enables us to see ourselves as part of history (Talking Back 110). The gendered nature of her statement suits the women's movement in its diversity of struggles. With regards to sexual violence survivors of all genders can find personal and political value in connecting with people who have had similar experiences. Therapeutic practitioners have recognized this for some time and have reported that group therapy settings can enable survivors to integrate the empathetic reactions they experience for other participants in their group into their own self-perceptions, and can encourage survivors to identify the cultural and historical factors responsible for the continuation of mass sexual violence today (Brison, Aftermath 63; Alcoff and Gray 283; Herman 224). Stand-up comedy as a culture-based therapeutic process can generate similarly positive responses. Although she doesn't address cultural or artistic therapeutic processes directly, Herman insists that, "Because trauma affects every aspect of human functioning, from the biological to the social, treatment must be comprehensive" (156). This is Cvetkovich's launching point - she also argues that progress from trauma must incorporate social and cultural elements, but asserts that this work can be effectively done outside of any clinical setting. She maintains that "Trauma cultures are actually doing the work 
of therapy" by collapsing the distinctions between affective and public life and putting the authority over treatment back into survivors' own hands (10). Clinical treatment can be lifesaving for many survivors but its historic privileging over any other form of therapeutic process has sidelined the development and promotion of other, perhaps invaluable, methods of integrating trauma.

Although the benefits of survivors bearing witness to the histories of other survivors are substantial the experience doesn't come without associated risks. While it can be liberatory for a survivor to learn that they are not alone and that the violence they have experienced is connected to larger schemas, that same knowledge can be alternatively interpreted as pointing towards a demoralizing and insurmountable situation (Brison, "Everyday" 193). Some survivor-centric stand-up shows enlist people trained in survivor support and active listening principles to make themselves available for any audience members triggered or otherwise upset by the material covered on stage. This initiative demonstrates consideration for the different impacts hearing jokes about sexual trauma can have on survivors and our allies. New directions in research might take up an analysis of the experiences of audience members at survivor-centric comedy shows. The arguments I have made regarding audiences positions have been generated from the perspectives of my interview participants - in other words, from people who are watching comedy as both audience members and practitioners themselves. Katie, who performed at a series of shows featuring survivors of sexual violence, described having this realization herself partway through her run:

I had a friend pick me up to take me to where I was staying and I was just [weeping]. "The world is a horrible place and everyone's in pain," and she was like, "No, you're just in a really specific context and that's a small version of the population," and I was like, "It's so 
many more than you ever think." It's just a lot. It's a lot. On one hand it's like, "You're not alone!" But then it's like, "You're not alone." I say this in my act, too. I wish that I could be the only person, because I can handle it. I wish that I can be the only person that this ever happened to, you know? So that no one else would have to go through it.

The conversation Katie had with her friend happened after she had been approached by a stream of audience members wanting to confide in her how meaningful they had found her performance. Earlier in our conversation she had mentioned, "Usually after I perform I like to hide, I don't like talking to people afterwards." For reasons outside of her control she was unable to leave the venue in time to avoid the people who wanted to speak with her, resulting in a breach of her boundaries and a loss of personal agency. No other participant reported such a punctual moment of distress connected to their interactions with audience members. Jordan Ross tackled how paralyzing coming to consciousness about the prevalence of sexual violence can be in this joke:

One of the things that's so funny is everyone is the Zooey Deschanel of their own rape. Everyone's like, [in falsetto] “Oh my God, I chipped a nail, my boss is mad at me, I got raped, but every day I work to be a better me!" What? You just lump it and you're like, "I will do better next time!” At what, exactly? ... It's this incredible thing where, the reason this happens is that it's easier to blame yourself, because if you blame yourself you can fix it. And if you blame them - anarchy. It's a scary world to live in.

In this bit Jordan Ross exposes how rape culture functions to encourage survivors of sexual violence to blame themselves for their own trauma. Shifting the responsibility of preventing further abuses onto the survivor absolves the wider community of any duty to critique and adjust their values and behaviour. As Jordan Ross comments, this perspective can be 
seductive to survivors who are struggling to make sense of the traumatic event(s) they have experienced while trying to recapture a feeling of being safe in the world. The tendency of rape survivors to blame themselves or to assume guilt for their own assaults is "practically universal" (Herman 53). Herman understands this as the survivor attempting to regain a sense of control over their life: "to imagine that one could have done better may be more tolerable than to face the reality of utter helplessness" (53). Survivors may alternate between feeling equipped to handle the realities of sexual violence and becoming overwhelmed by its prevalence in their lives depending on their changing social context. Nancy, who had completed a national tour of a show featuring survivors of sexual violence, reflected with me on her post-tour reaction:

I think that's what happened to me after the tour is I was like, "Holy shit, we pulled off the tour where we went across the country and everyone told me their shit! I could see in peoples' eyes how important this was to them, and who the fuck am I to hold that? That's insane. Get someone with a degree in this, get someone with a counselling background, get someone who has done their taxes recently. Holy shit, who the fuck am I?"

The social isolation many survivors experience can be unbearable. Our eagerness to participate in what Cvetkovich calls "trauma cultures - public cultures that form in and around trauma" is born in part from relief that we are no longer alone and no longer have to remain silent (9). Nancy and Simone, quoted earlier, refer to feeling inadequately prepared to handle disclosures of trauma. These feelings of inferiority may stem in part from our culture's emphasis on medical interventions as cures for trauma ("Get someone with a counselling background"; "I'm not a counsellor, I'm not qualified"), but, as neither participant promotes themselves as medically trained or certified, the intentionality of other survivors in reaching out to these participants is likely not in search of that type of service anyway. I would suggest, in fact, that 
some survivors are likely approaching these performers not despite their lack of counselling credentials, but because of that lack. Alcoff and Gray insist that "[w]e need to transform arrangements of speaking to create spaces where survivors are authorized to be both witnesses and experts, both reporters of experience and theorists of experience. Such transformations will alter existing subjectivities as well as structures of domination and relations of power" (282). Stand-up comedy by and for survivors can authorize survivors to joke and laugh on our own terms. Reflecting on their role as audience members themselves in the past, participants commented on what it was like for them to witness other survivor-comics telling jokes about sexual trauma. Avery commented that,

I definitely find the times I've seen people share sexual trauma based content, comedy especially, but just in general, from my perspective it unites survivors. It gives you another person on your list of who to call when you're freaking out about it.

Avery's list of who to call during moments of crisis is based at least in part on peoples' survivor status rather than their professional experience as trauma specialists. His perspective authorizes survivors not only as experts of their own experiences, but also as potentially having some expertise, based on those experiences, that could be beneficial to himself. Simone echoed this perspective and said that she feels more trusting towards other survivors than she does towards non-survivors, even when their experiences of violence are different from her own:

All of the [shows from the tour] were filmed and [the producers] made them accessible to everyone who was in the shows, so I got to watch everyone else's sets, and they were all so different, which is cool but sad at the same time, that everyone has the same experience but in so many different ways. I find it really cathartic, that's a word I've been using a lot, but it feels better because you know they went through what you went through, so right away 
they've got your attention, and you're like, "I trust you," right away, it's a trust thing. A lot of survivors have trust issues afterwards and it's easier to trust other survivors.

Trauma cultures generate living archives of feeling by creating spaces where survivors of sexual violence can meet and engage with each other. These encounters can, as Alcoff and Gray desire, alter survivors' subjectivities by introducing us to new affective relationships. Turning away from rape culture's mistrust and pathologization of survivors and towards an environment, as described by the participant above, where survivors are almost innately trustworthy, validates a feminist, pro-survivor structure of feeling. In this way traditional power structures are being circumvented and replaced by therapeutic processes enabled by trauma cultures and practices of trauma-based cultural production. Avery spoke to how he has built relationships with other comics who perform material about sexual trauma after witnessing their sets:

I've never seen too many people perform in-depth sexual trauma jokes. I've seen one or two and in those situations I checked in with them and made some cool friends, because it's sort of interesting when your trauma is the first thing you have in common with someone, before you even learn what else they do, that and comedy. That was kind of cool, because you're like, "Cool, those are two defining qualities of who I am, maybe we have a similar outlook," which is kind of cool. They only did one joke and it went over everybody else's head, but I definitely picked up that there probably was a lot more to it than just that. In this way a pro-survivor structure of feeling emerges within the context of a comedy show as those with "similar outlooks," as Avery described, based from their experiences with sexual trauma, recognize each other through shared laughter. 
Successful comedy relies on mutuality between the speaker and listener. A joke from Mayer's set is illustrative of this point. He describes how uncomfortable men who are not survivors become when he jokes with them about being raped by his uncle as a child. He says, I like to make people uncomfortable, that's a lot of fun for me. I like to mess with people, and I like to use my story to do that. And men do weird, stupid shit like we'll get together and argue and try to compete with, you know, who lost their virginity at a younger age. Men actually do this, which is stupid. So they'll be like, "Well I was 17 when I lost mine," and somebody else, "Well I was 16," and I always pipe up and ruin the conversation by going, "Well I was three." I was a sexy toddler, I had a bad uncle, it always shuts that conversation down.

The frosty reception he recounts in that bit stands in contrast to the audience reception of the joke audible in the video footage - with a crowd of survivors and allies present the piece draws laughter and applause. I return to Meyer's writing on safety here: relief humour depends on the stabilizing of perceived tension (312). When Mayer tells his male friends that he lost his virginity at three years old, he introduces tension into that conversation by breaching masculine codes of conduct and by destabilizing their previously held beliefs in safety and the rarity of childhood sexual violence. In that situation the instability is not resolved and, as Mayer comments, his disclosure "always shuts that conversation down." When the joke was transposed to the setting of a comedy club populated by survivors and our allies, the cycle of tension and relief was completed and humour was accomplished. Mayer introduces tension when he describes himself participating in the hyper-masculine ritual of boasting about sexual conquests. At this point in the set listeners already know that Mayer had been raped as a child, so the content of the line, "Well I was three," doesn't function as a surprise. In the video clip we can 
hear the audience murmur and groan in empathy at this point. It isn't until he finishes with, "I was a sexy toddler, I had a bad uncle, it always shuts that conversation down," that the audience laughs and cheers. The incongruity of the phrase 'sexy toddler' aside, this final line doesn't contain any wordplay or other linguistic humour that would spark a listener into laughter. Rather, the crowd experiences pleasure once Mayer's narrative concludes and he demonstrates, through his casual demeanour, that no harm has come to him. Listeners in this context likely have a high degree of familiarity with the anxiety of disclosing sexual violence and would be empathetic to Mayer's circumstances - some audience members, following the experience of the participants quoted above, may also feel trust in Mayer due to his survivor status. This mutuality between Mayer and his audience allows for the efficacy of the tension he introduces at the top of the joke and increases the surge of relief exhibited by the laughing audience at its close.

Witnessing a comic succeed with jokes about sexual trauma can inspire audience members to take up their own practices of cultural production. This structure of feeling is alive and growing in the very way Williams described, as having an "immediate and actual significance of being" (Marxism 130). The vitality of this structure of feeling is obvious as its cultural status shifts from the marginal to attracting some mainstream interest. Lisa commented on how she felt when she saw a comic perform material about their history of sexual trauma, long before she herself started performing similar content:

Like, I wanted to shout out loud kind of thing, it was really awesome. I was really excited but also at the same time wanted to pay laser attention to technically how she was doing it, how she set it up. I was really paying attention to that but also so excited just to hear her say it, and to see how well it was going over. It was very encouraging and inspiring and 
maybe if I did see more of it I would be more encouraged, inspired to do it in my own comedy. It planted a seed for sure, it's just still going to take a while.

Lisa spoke about having a genuine interest in producing comedy about sexual trauma, but sensed that the current structure of feeling surrounding that mode of cultural production was still too sparse for her to do so safely. The community-building potential of humour discussed above not only connects survivors with each other, but can also link people interested in a certain style of cultural production, fortifying a budding structure. Survivors telling rape jokes is still an emerging style of comedy but, as Williams writes, although a structure of feeling may be in its emergent stage, it can still exert considerable cultural pressure (Marxism 132). The sociality of comedy combined with humour's unique cognitive and linguistic tricks and the subversive position wielded by the survivor speaking as an authority on stage delivers a dynamic discursive resistance to the dominance of rape culture. 


\section{CONCLUSIONS}

The combined fields of trauma and humour studies present an enormous array of potential research directions, most of which necessarily fell outside of the scope of this project. By taking up stand-up comedy as my site of inquiry I was able to put forward some thoughts on the in-person experiences of performing and witnessing jokes about sexual trauma. This research could be built upon by pairing interview data with ethnographic methods like participant observation. Taking notes from the green room before the show and recording comics' reactions after they leave the stage would allow a researcher to attend to the affective dimensions of performing with more immediacy than was included here. Analyses of the relationships between trauma and the body, both in terms of performers themselves as well as regarding audience members would offer great contributions to critical feminist cultural research on trauma. A greater recognition and parsing of demographic data, particularly as concerns race, class, ability, and gender is essential for future work. The conclusions I have drawn from the insights offered to me by the participants I interviewed cannot be assumed to be representative of all survivors or survivor comics practicing in this moment.

Broader applications of the research presented here suit a range of comedic styles and texts. Investigations into a variety of media are warranted. One of my first encounters with a survivor joking about rape was Patricia Lockwood's poem, "Rape Joke.” Questions I might here ask would include, how do the conventions of poetry influence survivors' work? How does Lockwood's poem fit into the traditions of writing comedic poetry? Of writing sexual violence into verse? How does it break from them? From Lockwood's work I drifted towards audiovisual material and found Jessie Kahnweiler's short film “Meet My Rapist.” Kahnweiler frames disclosing rape to her friends and family as instead introducing them to a strange and 
unappealing new boyfriend. Uploaded onto YouTube the video is accessible to a wide audience. An investigation into the comments left by viewers of the film might offer insight into how users are responding to humour about rape produced by survivors, while an analysis of the diegetic material itself could expand on existing ideas about how survivors are using irony and satire to represent living with sexual trauma. These suggestions are of course not exhaustive, but are merely meant to point towards an understudied trend in survivor speech across different forms of media. Scholars interested in pursuing politically meaningful work with survivors of sexual violence will find a living cultural archive ripe with comedic innovation.

What this thesis has done is engaged critically with survivors' humour and laughter on their own terms. It happens far too often in our rape culture that survivors are only called upon to respond to the jokes and laughter of which we are the target - misogynist rape jokes are still disappointingly common among celebrity and amateur performers alike. My work pushes those jokes aside for once and announces instead that the survivors referenced here are brilliant, innovative, and curious comics in their own right. They are doing the personal and culturally therapeutic work of making sense of trauma; their representations of violence and its aftermaths use wordplay, surprise, incongruity and cycles of purposefully manipulated tension and relief to articulate pain in linguistically, cognitively, and affectively novel ways. The preceding chapters have pointed towards different dimensions of this work: my analysis of the comics' experiences writing and performing their own material highlighted the utility of working through trauma in language and the potential benefits of sharing those testimonies with a club audience. Participants found that opening themselves up to exchanges with other survivors in spaces that centred their comfort were transformative, both in terms of impacting how they defined their own experiences of violence and in coming to consciousness about the ubiquity of sexual 
violence in their communities and across Canada. Rape prevention programming that involves humour can be impactful as we struggle to reduce these appalling rates of sexual violence nationwide. Jokes that compel us to hold two or more disparate ideas in our minds at once open possibilities for empathy, critical self-reflection, and the transmission of new information and opinions. But of course it is not the duty of the marginalized to educate their oppressors on how to avoid causing further harm; survivors' jokes have intrinsic value beyond their capacity to present an entertaining rebuke to rape culture. Comedy by and for survivors helps us gain footholds in our pain and offers new visions of a future for ourselves - not beyond trauma, per se, but somewhere other than eternally captive in the dingy doldrums it had previously assumed we would inhabit.

Although my emphasis here has of course been on the comedic, my goal with this research has never been to discard feelings of sadness or grief. Instead, I aimed to recognize, as Duggan writes, that "there is, it would seem, pleasure in the unpleasurable" (1) and that it is possible and common for us to hold both at once; that trauma impacts and implicates the full range of human feeling and that some survivors want to leave us remarking, as Avery hoped his listeners would, "Aw man, that guy's sad... But he killed." 


\section{WORKS CITED}

Ahmed, Sara. The Cultural Politics of Emotion. Routledge, 2004.

Alcoff, Linda, and Laura Gray. "Survivor Discourse: Transgression Or Recuperation?" Signs, vol. 18, no. 2, 1993, pp. 260-290 doi:10.1086/494793.

Althusser, Louis. "Ideology and Ideological State Apparatuses (Notes Towards an Investigation)." Media and Cultural Studies KeyWorks, edited by Meenakshi Gigi Durham and Douglas M. Kellner, Wiley-Blackwell, 2009, pp. 79-87.

Alvesson, Mats, and Kaj Sköldberg. Reflexive Methodology: New Vistas for Qualitative Research, SAGE, 2009.

Baxter, Judith. Positioning Gender in Discourse: A Feminist Methodology. Palgrave Macmillan, 2003.

Baxter, Judith. "Feminist Post-Structuralist Discourse Analysis - A New Theoretical and Methodological Approach?” Gender and Language Research Methodologies, edited by Kate Harrington, Lia Litosseliti, Helen Sauntson, and Jane Sunderland, Palgrave Macmillan, 2008, pp. 234-256.

Benjamin, Walter. "The Author as Producer." New Left Review, no. 62, 1970, pp. 83.

Billig, Michael. Laughter and Ridicule: Towards a Social Critique of Laughter, Sage, 2005.

Bishop, Wendy. Teaching Lives: Essays and Stories. Utah State University Press, 1997.

Braidotti, Rosi. Embodiment and Sexual Difference in Contemporary Feminist Theory. Columbia University Press, 1994.

Brison, Susan. "Surviving Sexual Violence: A Philosophical Perspective." Journal of Social Philosophy, vol. 24, no. 1, 1993, pp. 5-22 doi:10.1111/j.1467-9833.1993.tb00493.x.

Brison, Susan. Aftermath: Violence and the Remaking of a Self. Princeton University Press, 2003. 
Brison, Susan J. "Everyday Atrocities and Ordinary Miracles, Or Why I (Still) Bear Witness to Sexual Violence (but Not Too often)." Women's Studies Quarterly, vol. 36, no. 1/2, 2008. , pp. 188-198 doi:10.1353/wsq.0.0060.

Butler, Judith. Excitable Speech: A Politics of the Performative. Routledge, 1997.

Butler, Judith. “Critically Queer.” GLQ, vol. 17, no. 32, 1993, pp. 17-32.

Campbell, Rebecca, and Adrienne E. Adams. "Why do Rape Survivors Volunteer for Face-toFace Interviews?: A Meta-Study of Victims' Reasons for and Concerns about Research Participation." Journal of Interpersonal Violence, vol. 24, no. 3, 2009; 2008;., pp. 395405 doi:10.1177/0886260508317192.

Campbell, Rebecca, et al. "Training Interviewers for Research on Sexual Violence: A Qualitative Study of Rape Survivors' Recommendations for Interview Practice." Violence Against Women, vol. 15, no. 5, 2009, pp. 595-617 doi:10.1177/1077801208331248.

Cavanagh, Sheila. "Introduction to Queer Theory.” Critical Sexuality, 18 Jan. 2017, York University, Toronto ON. Lecture.

Cixous, Hélène. "Laugh of the Medusa." New French Feminisms: An Anthology, edited by Elaine Marks and Isabelle de Courtivron, University of Massachusetts Press, 1980, pp. 245-264.

Cox, Lara. "Standing Up Against the Rape Joke: Irony and its Vicissitudes." Signs, vol. 40, no. 4, 2015., pp. 963-984 doi:10.1086/680330.

Cvetkovich, Ann. An Archive of Feelings: Trauma, Sexuality, and Lesbian Public Cultures. Duke University Press, 2003.

Davis, Diane. Breaking Up [at] Totality: A Rhetoric of Laughter. Southern Illinois University Press, 2000. 
Disch, Estelle. "Research as Clinical Practice: Creating a Positive Research Experience for Survivors of Sexual Abuse by Professionals." Sociological Practice, vol. 3, no. 3, 2001., pp. 221-239 doi:10.1023/A:1011526211933.

Doolittle, Robyn. "Unfounded: Why Police Dismiss 1 in 5 Sexual Assault Claims as Baseless." The Globe and Mail, 3 Feb. 2017, http://www.theglobeandmail.com/news/investigations/unfounded-sexual-assault-canadamain/article33891309/. Accessed 10 Mar. 2017.

Duggan, Patrick. Trauma-Tragedy: Symptoms of Contemporary Performance. Manchester University Press, 2012.

Du Pré, Athena. Humor and the Healing Arts: A Multimethod Analysis of Humor use in Health Care, Erlbaum, 1998.

Fahs, Breanne. "Naming Sexual Trauma: On the Political Necessity of Nuance in Rape and Sex Offender Discourses." Critical Trauma Studies: Understanding Violence, Conflict, and Memory in Everyday Life, edited by Monica J. Casper and Eric Wertheimer, New York University Press, 2016, pp. 61-77.

Femifesto. Use the Right Words: Media Reporting on Sexual Violence in Canada. Femifesto, 2015, http://www.femifesto.ca/wp-content/uploads/2015/12/UseTheRightWords-SingleDec3.pdf

Foubert, John D., Eric E. Godin, and Jerry L. Tatum. "In their Own Words: Sophomore College Men Describe Attitude and Behavior Changes Resulting from a Rape Prevention Program 2 Years After their Participation." Journal of Interpersonal Violence, vol. 25, no. 12, 2010., pp. 2237-2257 doi:10.1177/0886260509354881.

Foucault, Michel. The History of Sexuality Volume 1: An Introduction. Pantheon Books, 1978. 
Foucault, Michel. The Order of Things: An Archaeology of Human Sciences. Vintage Books, 1994.

Gilmore, Leigh. The Limits of Autobiography: Trauma and Testimony. Cornell University Press, 2001.

Hall, Stuart. "Encoding/Decoding.” Media and Cultural Studies KeyWorks, edited by Meenakshi Gigi Durham and Douglas M. Kellner, Blackwell Publishing, 2001, pp. 166-176.

Hall, Stuart. "Notes on Deconstructing 'the Popular." Cultural Theory and Popular Culture: A Reader, edited by John Storey, Pearson/Prentice Hall, pp. 442-453.

Harding, Sandra. "A Socially Relevant Philosophy of Science? Resources from Standpoint Theory's Controversiality." Hypatia, vol. 19, no. 1, 2004, pp. 25-47, doi:10.1111/j.15272001.2004.tb01267.x.

Herman, Judith Lewis. Trauma and Recovery. HarperCollins, 1992.

Hodges Hamilton, Amy. "First Responders: A Pedagogy for Writing and Reading Trauma." Critical Trauma Studies: Understanding Violence, Conflict, and Memory in Everyday Life, edited by Monica J. Casper and Eric Wertheimer, New York University Press, 2016, pp. 179-204.

hooks, bell. Talking Back: Thinking Feminist, Thinking Black. Between the Lines, 1988. hooks, bell. Feminism is for Everybody: Passionate Politics, South End Press, 2000. Jackson, Debra. "Answering the Call: Crisis Intervention and Rape Survivor Advocacy as Witnessing Trauma." Critical Trauma Studies: Understanding Violence, Conflict, and Memory in Everyday Life, edited by Monica J. Casper and Eric Wertheimer, New York University Press, 2016, pp. 205-226. 
Jensen, Meg. "Surviving the Wreck: Post-Traumatic Writers, Bodies in Transition and the Point of Autobiographical Fiction." Life Writing, vol. 13, no. 4, 2016, pp. 431-448, doi:10.1080/14484528.2016.1141034.

Jordan Ross, Heather. "Rape is Real and Everywhere: Heather Jordan Ross in Halifax." YouTube, uploaded by Rape is Real, 19 Jan. 2017, https://www.youtube.com/watch?v=vW6FZ6hxcSg

Kahnweiler, Jessie. “Meet My Rapist.” YouTube, uploaded by Jessie Kahnweiler, 16 Sept. 2013, https://www.youtube.com/watch?v=_bAAPkqn8Q0

Leclerc, Annie. "Woman's Word.” New French Feminisms: An Anthology. Edited by Elaine Marks and Isabelle de Courtivron, University of Massachusetts Press, 1980, pp. 79-86

Lockwood, Patricia. "Rape Joke.” The Awl, 25 Jul. 2013, accessed on 9 Feb. 2017, www.theawl.com/patricia-lockwood-rape-joke-2e9bd41d80b1\#.jzjw3528t

Mayer, Nelson. "Nelson Mayer: Rape Is Real \& Everywhere (May 20, 2016).” YouTube, uploaded by The Unusual Suspects, 23 Aug. 2016, https://www.youtube.com/watch?v=B1ytMmshnio

Maxwell, Ashley. “Adult criminal court statistics in Canada, 2013/2014.” Statistics Canada 30 Nov. 2015, http://www.statcan.gc.ca/pub/85-002-x/2015001/article/14226-eng.htm Mayo, Cris. "Incongruity and Provisional Safety: Thinking through Humor." Studies in Philosophy and Education, vol. 29, no. 6, 2010., pp. 509-521doi:10.1007/s11217-0109195-6.

McDonald, Susan, et al. Bill C-46: Records Applications Post-Mills, A Caselaw Review. Department of Justice Canada, 2004. 
Meyer, John C. "Humor as a Double - Edged Sword: Four Functions of Humor in Communication." Communication Theory, vol. 10, no. 3, 2000., pp. 310-331 doi:10.1111/j.1468-2885.2000.tb00194.x.

Payne, Michelle. 2000. Bodily Discourses: When Students Write about Abuse and Eating Disorders. Portsmouth, NH: Boynton/Cook.

Perreault, Samuel. “Criminal Victimization in Canada, 2014.” Statistics Canada 30 Nov. 2015, http://www.statcan.gc.ca/pub/85-002-x/2015001/article/14241-eng.htm\#a8 Accessed 20 Jan. 2017.

Projansky, Sarah. Watching Rape: Film and Television in Postfeminist Culture. New York University Press, 2001.

Rich, Marc D. "The interACT Model: Considering Rape Prevention from a Performance Activism and Social Justice Perspective." Feminism \& Psychology, vol. 20, no. 4, 2010., pp. 511-528doi:10.1177/0959353510371366.

Rich, Marc D., et al. "“I'd rather be Doing Something Else:” Male Resistance to Rape Prevention Programs." The Journal of Men's Studies, vol. 18, no. 3, 2010., pp. 268-288 doi:10.3149/jms.1803.268.

Rolin, Kristina. "Standpoint Theory as a Methodology for the Study of Power Relations." Hypatia, vol. 24, no. 4, 2009, pp. 218-226, doi:10.1111/j.15272001.2009.01070.x.

Ronell, Avital. “Interview with Avital Ronell.” Interviewed by Andrea Juno. Re/search: Angry Women no. 13. San Francisco: Research Publications, 1991. 127-53.

Rouse, Joseph. "Standpoint Theories Reconsidered." Hypatia, vol. 24, no. 4, 2009, pp. 200-209, doi:10.1111/j.1527-2001.2009.01068.x. 
Scarry, Elaine. The Body in Pain: The Making and Unmaking of the World. Oxford University Press, 1987.

Schwab, Gabriele M. "Voices of Silence: On Speaking from within the Void (A Response to Shahla Talebi)." Critical Trauma Studies: Understanding Violence, Conflict, and Memory in Everyday Life, edited by Monica J. Casper and Eric Wertheimer, New York University Press, 2016, pp. 111-121.

Stevens, Maurice E. "Trauma Is as Trauma Does: The Politics of Affect in Catastrophic Times." Critical Trauma Studies: Understanding Violence, Conflict, and Memory in Everyday Life, edited by Monica J. Casper and Eric Wertheimer, New York University Press, 2016, pp. 19-36.

van der Kolk, Bessel A. "Trauma and Memory." Psychiatry and Clinical Neurosciences, vol. 52, no. S1, 1998., pp. S97-S109 doi:10.1046/j.1440-1819.1998.0520s5S97.x.

Wertheimer, Eric and Casper, Monica J. "Within Trauma." Critical Trauma Studies: Understanding Violence, Conflict, and Memory in Everyday Life, edited by Monica J. Casper and Eric Wertheimer, New York University Press, 2016, pp. 1-16.

Wicks, Amanda. "'No Other Tale to Tell': Trauma and Acts of Forgetting in The Road." Critical Trauma Studies: Understanding Violence, Conflict, and Memory in Everyday Life, edited by Monica J. Casper and Eric Wertheimer, New York University Press, 2016, pp. 135156.

Williams, Raymond. "Culture is Ordinary." Resources of Hope: Culture, Democracy, Socialism, edited by Robin Gable, Verso Publishing, 1989, pp. 3-18.

Williams, Raymond. Marxism and Literature. Oxford University Press, 1977. 
Wynter, Sylvia. "Rethinking 'Aesthetics': Notes Towards a Deciphering Practice.” Ex-iles:

Essays on Caribbean cinema, edited by Mbye Cham, Africa World Press, 1992, pp. 237279. 